\title{
La conservación del arte rupestre en las sierras del Campo de Gibraltar. Un primer diagnóstico
}

\author{
Martí Mas Cornellà 1 \\ Jesús F. JORDÁ PARDO ${ }^{2}$ \\ Jaume CAMBra SÁnchez ${ }^{3}$ \\ JOSEP MAS RIERA ${ }^{4}$ \\ ANTONI LOMBarte CarRera ${ }^{5}$
}

Entre 1988 y 1993 desarrollamos una primera fase del proyecto de investigación arqueológica Las manifestaciones rupestres prehistóricas de la zona gaditana ${ }^{6}$, dentro del cual planteamos, desde una perspectiva interdisciplinar, un diagnóstico del estado de conservación de los yacimientos objeto de estudio. El objetivo era definir las técnicas de reproducción más adecuadas e iniciar un debate en torno a las medidas de protección o conservación necesarias, pero no se pretendía aportar soluciones inmediatas, muchas veces simplistas, provisionales e incluso contraproducentes.

El proyecto citado ha abordado la documentación de las pinturas y grabados localizables en más de cien estaciones, abrigos rocosos, situadas en las sierras que bordean la antigua Laguna de la Janda, en el Campo de Gibraltar y zonas próximas (como Sierra Momia o Sierra

1 Departamento de Prehistoria e Historia Antigua de la Universidad Nacional de Educación a Distancia, Madrid.

2 Area de Ingeniería Geoambiental del Instituto Tecnológico Geominero de España, Madrid.

3 Departament de Biologia Vegetal de la Universitat de Barcelona.

4 Institut de Ciències del Mar del Consejo Superior de Investigaciones Científicas, Barcelona.

${ }^{5}$ Institut de Ciències del Mar del Consejo Superior de Investigaciones Científicas, Barcelona.

${ }_{6}$ Actividades arqueológicas autorizadas y subvencionadas por la Dirección General de Bienes Culturales de la Consejeria de Cultura de la Junta de Andalucia. 
Blanquilla) ${ }^{7}$ (fig. 1). Hasta ahora se ha actuado en treinta y cinco cavidades de Sierra Momia y Sierra del Niño (figs. 2 y 3). No vamos a entrar en consideraciones en relación con el horizonte cultural o cronológico de estas manifestaciones artísticas ni tendremos en cuenta sus peculiares características por haber sido ampliamente tratadas en otros articulos (Mas Cornellà, 1993). Este supone, en cierta forma, el desarrollo de una comunicación presentada en el XIX Congreso Nacional de Arqueología (Mas Cornellà, 1989) en donde esbozamos un primer planteamiento, cuyos resultados exponemos aquí, y aportábamos una síntesis historiográfica de las referencias sobre el estado de conservación de estos documentos recogidas en los trabajos de los investigadores pioneros, de principios de siglo.

Es evidente que el principal factor que incide en la degradación de estas manifestaciones rupestres es la acción antrópica que viene agravándose en los últimos años a medida que aumenta la afluencia de visitantes a estos lugares, antes escasamente concurridos (figs. 4 y 5). El turismo incontrolado es un elemento negativo para la conservación de estos sitios, pero no deben olvidarse las actitudes conscientes o inconscientes de corcheros, carboneros, pastores, cazadores... cuando se refugian casualmente en cavidades que podrian considerarse inaccesibles al gran público.

Intentaremos, sin ninguna pretensión de exhaustividad, redactar una lista de agresiones de este tipo. En el caso del Conjunto rupestre del Tajo de las Figuras actualmente y desde hace algunos años están minimizadas por contar con vigilancia, pero observamos evidencias de acciones antiguas, como superficies gravemente deterioradas tanto por la existencia de panales de abejas como por su eliminación y otras partes en las que las paredes muestran profundas estrías provocadas seguramente por haberse quitado los nidos de avispas terreras (fig. 6) en la Cueva del Tajo de las Figuras (fig. 7), un abrigo en el que tradicionalmente se habian venido mojando las pinturas desde su descubrimiento ${ }^{8}$.

7 Aunque realmente, y según el sistema ciudades propuesto en 1986 por la Junta de Andalucia, estamos trabajando en dos comarcas administrativas, Medina Sidonia y Algeciras, creemos que la zona en que nos movemos puede ser definida en términos de comarca natural como Sierras del Campo de Gibraltar o Sierras del Aljibe.

\& Cabe decir, sin embargo, que a pesar de ser una práctica totalmente inaceptable, no es la única causa de la capa de alteración que presentan los paneles pintados y grabados de esta estación, como veremos a continuación. Aunque teniendo en cuenta que éste no tenía porqué ser el único líquido utilizable, en 1988 realizamos unos completos análisis de parámetros bióticos y abióticos del agua de dos manantiales muy próximos a la Cueva del Tajo de las Figuras que revelaron que se trata de agua poco ácida, cuyos 
Podríamos continuar la relación destacando un gran número de inscripciones grafiteadas en la Cueva del Tesoro o de la Paja y en la de Luis Lázaro, aquí justo encima de la composición pictórica. Esta última, al igual que la Cueva Negra de las Pradillas, con piqueteados exactamente sobre las escasas pinturas que contiene, y no en otras partes, puede considerarse un lugar no conocido y difícilmente visitable. Los grafitos o pintadas, algunas de grandes dimensiones, los encontramos especialmente en las Cuevas de los Ladrones o Pretinas 1 y 4 (fig. 8) y en Palomas 1, en donde afectan notablemente a pinturas postpaleolíticas. Aqui se ha improvisado una mesa y algunos asientos con piedras de considerable tamaño, alrededor de las cuales puede verse abundante cantidad de basura (fig. 9). Uno de los lugares más afectados es el Conjunto rupestre de Bacinete, su fácil accesibilidad, la belleza del paraje y el conocimiento generalizado de su existencia contribuyen a que sea muy visitado. En el Gran Abrigo hay varias pintadas, entre ellas una que indica prohibido manchar, y un gran número de piqueteados y letras grabadas sobre las representaciones, ejecutadas sobre un soporte muy fragmentado (fig. 10). En el Abrigo 5 hemos constatado que unos trozos de la pared han sido arrancados -parece un intento de expoliación relativamente reciente- $y$ ha desaparecido una interesante figura (fig. 11).

Cabe destacar, como desagradable anécdota, que en un abrigo situado a unos sesenta metros de la Cueva de la Paja o del Tesoro, conocido como Cueva del Curtido, se localizaron unas pinturas falsas que intentan imitar manifestaciones artísticas prehistóricas (paleolíticas y postpaleolíticas), inscripciones protohistóricas..., y presentan rasgos similares al arte brut (fig. 12). Están ejecutadas con diversas sustancias en polvo y se utilizaron como aglutinante materias grasas, según pudimos constatar a partir de un diagnóstico ocular el 26 de junio de 1986. En una nueva observación, el 26 de octubre, tres meses después, vimos que se había añadido una nueva inscripción.

Todas estas agresiones las encontramos, en mayor o menor grado, repetidas continuamente en los abrigos que vamos estudiando, destacando también las paredes ahumadas o los restos dejados por las hogueras, sin olvidar, tampoco, la acción de los animales. Ganado bravo, vacas retintas, ciervos, corzos, gamos, jabalíes, cabras, buitres..., utilizan los abrigos como refugio (la mayoría de los lugares están dentro de cotos

componentes físico-químicos están representados en cantidades insignificantes, exceptuando la sílice (muestreo de campo realizado por el Laboratorio de la Delegación Provincial de la Consejeria de Salud y Servicios Sociales de la Junta de Andalucia en Cádiz). 
privados de caza o ganaderías dedicadas al vacuno, actividades que han desplazado prácticamente a la tradicional, el ganado cabrío). En algunos casos han sido adaptados como majada o corral, y los animales rozan las paredes, defecan en el suelo, suele haber muchas veces una gruesa capa de excrementos, o miccionan en las paredes (murciélagos), como es muy evidente, por ejemplo, en la Cueva del Tajo de las Figuras.

Al realizar el trabajo de campo de reproducción y estudio directo del arte rupestre de esta zona hemos documentado todas las evidencias de estas características (muros - algunas cavidades han estado habitadas incluso en tiempos recientes o utilizadas como tenada o pajar-, basura, pintadas, grafitos, figuras arrancadas, zonas ennegrecidas...), así como también los procesos de tipo litogénico (soportes fragmentados, desconchados, exudaciones, bloques desprendidos, oxidaciones de hierro, grietas...), orgánico (liquenes, algas, hongos, briófitos, pequeñas plantas o matorrales, nidos de insectos o aves...) o la incidencia de fenómenos metereológicos (lluvia, viento, insolación...) sobre las cavidades y paneles con representaciones pintadas o grabadas. Sin embargo, para aproximarnos con una mayor precisión al estado de conservación de los yacimientos y la roca soporte desarrollamos puntualmente estudios geológicos, botánicos y zoológicos, en determinados lugares, cuyos resultados exponemos a continuación.

\section{ESTUDIO GEOLOGICO ${ }^{9}$}

Los estudios geológicos llevados a cabo tuvieron como objetivo la caracterización geológica de las rocas soporte de las manifestaciones artísticas rupestres, así como la determinación de las posibles alteraciones que sufriesen dichos materiales. Para lograr su consecución se abordaron dos niveles o escalas de aproximación:

- Escala regional: Estudio del contexto geológico general en el que se inscriben las cavidades, prestando especial atención a las formaciones geológicas sobre las que se desarroilan.

- Escala puntual: Análisis detallado de las características litológicas, sedimentológicas, estratigráficas, estructurales y geomorfológicas de las rocas sobre las que se desarrollan todas y cada una de las cavidades.

9 Este trabajo es fruto de una estrecha colaboración entre el Area de Ingeniería Geoambiental del Instituto Tecnológico Geominero de España, institución a la que se solicitó el estudio y que ha facilitado la infraestructura necesaria para la realización de todos los análisis en sus laboratorios generales, y el proyecto de investigación arqueológica Las manifestaciones rupestres prehistóricas de la zona gaditana. 
Para una mayor operatividad estructuramos el trabajo de investigación en tres grandes fases a través de las cuales tratamos los diferentes aspectos del estudio:

- Trabajo de gabinete: Comprende el análisis de la cartografía existente, tanto geológica como topográfica, la interpretación de las fotografías aéreas y la revisión de la bibliografía precedente.

- Trabajo de campo: Incluye el reconocimiento sobre el terreno de las diferentes cavidades que componen los conjuntos rupestres del Tajo de las Figuras, Abrigos de Bacinete y Cuevas de Palomas, y el muestreo de las rocas soporte para posteriores análisis. A este respecto tenemos que hacer constar que las citadas muestras fueron obtenidas en puntos que no afectan de forma alguna a los paneles pictóricos ni al conjunto visual de las cavidades, siendo sin embargo significativas. Esta fase la llevamos a cabo durante dos campañas correspondientes a los años 1989 y 1991.

- Trabajo de laboratorio: Por un lado, efectuamos análisis petrográficos de las muestras de las rocas soporte obtenidas, mediante la realización de láminas delgadas para su estudio al microscopio petrográfico. Por otro, encargamos análisis geoquímicos para la determinación de la composición química y mineralógica de las muestras que así lo exigían.

A partir de todos los datos obtenidos realizamos la valoración de las caracteristicas intrinsecas de las rocas soporte y de las causas de su alteración, con objeto de evaluar los problemas que puedan plantearse de cara a su futura conservación. Los resultados quedan reflejados en el presente artículo.

Situación geológica de los conjuntos rupestres estudiados

El Conjunto rupestre del Tajo de las Figuras se encuentra enclavado en Sierra Momia (fig. 2), mientras que los Abrigos de Bacinete y las Cuevas de Palomas (fig. 13) se localizan en Sierra del Niño (fig. 3). Todos estos accidentes geográficos están situados en las Unidades Alóctonas del Campo de Gibraltar, dentro de las Cordilleras Béticas. Estas unidades forman un conjunto de mantos y escamas completamente desenraizados, constituidos principalmente por formaciones cretácicas y terciarias, en las cuales las de tipo Flysch tienen una muy importante representación (Fontoboté y Vera, 1983). Una de estas unidades que componen el Complejo del Campo de Gibraltar es la Unidad del Aljibe, situada entre el Senoniense (Cretácico superior) y el Burdigaliense (Mioceno medio), y es en una de las formaciones que culminan esta unidad, con- 
cretamente la Formación Areniscas del Aljibe, en donde se desarrollan las cavidades que componen los conjuntos rupestres que nos ocupan.

La Formación Areniscas del Aljibe (Gavala, 1916, 1929; Fontboté, 1983; ITGE, 1991) llega a alcanzar una potencia de $2.000-1.500 \mathrm{~m}$ y está formada predominantemente por areniscas de aspecto masivo, que son exclusivamente silíceas y tienen una coloración blanquecina o amarillenta en fractura fresca, que pasa a parda por meteorización, con finas intercalaciones de materiales pelíticos de color marrón claro. Son unas areniscas constituidas por granos de cuarzo, bien redondeados, de tamaño pequeño a grueso, a veces conglomeráticas, con apenas matriz de limos y arenas de grano muy fino y mala cementación, de tipo ferruginoso, no muy consistentes, por lo que la roca tiene una cierta friabilidad. Se presentan en bancos potentes que destacan en el relieve, con estructuras sedimentarias que indican claramente que estas areniscas se depositaron por corrientes de turbidez densas, en la parte media de abanicos submarinos profundos, observándose facies propias de lóbulos deposicionales y facies canalizadas. Las medidas de paleocorrientes permiten suponer una procedencia del S. Están afectadas por inestabilidades tectónicas, pudiéndose observar estructuras de deslizamiento, diques de arena, etc. Apenas contienen fósiles, por lo que su datación paleontológica es prácticamente imposible. No obstante, el techo de los materiales que descansan por debajo de las Areniscas del Aljibe tiene una edad Aquitaniense, mientras que las arcillas con intercalaciones de arenas que se sitúan a techo de las Areniscas del Aljibe, tienen una edad Aquitaniense superiorBurdigaliense. Por tanto, las Areniscas del Aljibe se depositan una vez iniciado el Aquitaniense, terminando su sedimentación en un momento no precisado, anterior al Aquitaniense superior-Burdigaliense. Estas areniscas se pueden correlacionar claramente con el llamado Manto Numídico al otro lado del Estrecho de Gibraltar (Fontboté, 1983).

Las areniscas del Aljibe están claramente tectonizadas por la Orogenia Alpina, encontrándose en la zona de Sierra Momia formando un sinclinal tumbado, cuyo eje tiene una dirección NW-SE, presentando un buzamiento invertido de $55^{\circ} \mathrm{SW}$ en la zona que nos ocupa. En Sierra del Niño se observa un plegamiento con sistemas de sinclinales y anticlinales tumbados como el de las Cuevas de Palomas. Esta formación se encuentra cortada por numerosas fallas normales de dirección EW y SW-NE, algunas de cierta extensión, produciendo desplazamientos verticales y horizontales en los materiales plegados. En los planos de estas fallas, claras zonas de debilidad, es frecuente el desarrollo de cavidades, como es el caso de la Cueva del Tajo de las Figuras. También se encuentra afectada esta formación por despegues que dan lugar a importantes cicatrices como la de la zona de Bacinete. 
Geomorfológicamente las Areniscas del Aljibe destacan en el relieve, dando lugar a varias alineaciones montañosas como Sierra Momia y Sierra del Niño, limitadas por áreas deprimidas, cuyo mejor exponente es la Laguna de la Janda, antiguo humedal de gran importancia para las comunidades de aves migratorias, que ha sido desecada por la intervención humana en épocas recientes. Estas sierras presentan la peculiaridad de contener numerosas cavidades o abrigos rocosos, de pequeño tamaño, originadas por corrosion y erosión eólica, junto con superficies corroidas en extensión, dando lugar en conjunto a una morfologia de tafonis en areniscas silíceas.

\section{Descripción de las cavidades}

A continuación describiremos brevemente las características geológicas y geomorfológicas más notables de algunas cavidades que contienen manifestaciones artísticas, dentro de los conjuntos rupestres del Tajo de las Figuras (Cuevas del Tajo de las Figuras, del Arco, Cimera o de los Cochinos, Negra, Alta, del Tesoro o de la Paja y de los Pilones), Abrigos de Bacinete (Gran Abrigo y 5) y Cuevas de Palomas (1 y 2). Como puede observarse del primer conjunto se han considerado todos los yacimientos, mientras que de los dos últimos se han elegido dos de los ocho y cuatro que engloban respectivamente.

Cueva del Tajo de las Figuras (figs. 7 y 19): Es una cavidad de tipo abrigo rocoso, con una sección subcircular que hacia el interior pasa a elíptica, disminuyendo de diámetro progresivamente, y cuya boca se encuentra en una pared rocosa casi vertical constituida por un plano de falla, salvando un desnivel sobre la topografía de unos cuatro metros. La visera del abrigo está parcialmente derrumbada, produciendo un caos de bloques en la base de la pared rocosa. Está desarrollada en unas areniscas de grano fino, aunque en determinados puntos son de grano medio y grueso, con laminación paralela, oblicua o cruzada, muy fina, marcada por óxidos de hierro, lo que le confiere una tonalidad rosada dentro del color amarillo claro. Estas areniscas están estratificadas en bancos de 0,5 a $1 \mathrm{~m}$ de espesor, constituidos internamente por láminas milimétricas, y están afectadas por una fracturación vertical o subvertical con planos de dirección EW, que se pueden apreciar por desplazamientos centimétricos en los planos de estratificación. Las superficies de la cavidad son netamente cóncavas, subesféricas, encontrándose la zona del suelo libre de sedimentos y muy pulimentada por el pisoteo y por la escorrentía superficial, mientras que en las paredes y el techo se presenta la roca con un aspecto más fresco. Hacia la parte media la cavidad presenta una sección en forma de botella, con el estrangulamiento 
en su parte superior. Las superficies del techo y paredes están afectadas por numerosas alteraciones de diversa índole tales como: huecos circulares centimétricos producidos por la acción eólica, escamamientos a favor de los planos de laminación cuando éstos son tangentes a la pared y pulimentos eólicos.

Cueva del Arco (fig. 19): Situada topográficamente por encima de la anterior, la Cueva del Arco aparece casi culminando el resalte topográfico del Tajo de las Figuras. Su boca es de sección elíptica y forma un gran arco, dado que la bóveda ha sido totalmente desmantelada por la erosión, al estar el techo casi en contacto con la superficie topográfica exterior, originándose una ventana cenital de gran amplitud. En la entrada hay un caos de bloques producto de los derrumbes de la visera y bóveda. La parte más interna del arco es un plano de fractura vertical. Las características de la roca encajante son similares a las descritas anteriormente, destacando la presencia de paquetes granocrecientes y de zonas de geometría subesférica con marcada cementación y óxidos de hierro. Las alteraciones son básicamente las mismas que en la Cueva del Tajo de las Figuras, observándose oquedades entre superficies de laminación más cementadas.

Cueva Cimera o de los Cochinos (fig. 19): Similar a las anteriores, aunque de menores dimensiones, con una sección elíptica, desarrollándose la entrada sobre un plano de fractura vertical. En el suelo se encuentran bloques y cantos autóctonos, junto con arenas siliceas procedentes de la erosión eólica sobre la cavidad.

Cueva Negra: Está constituida por los restos de una cavidad mayor dispuesta subhorizontalmente de la que sólo queda el fondo.

Cueva Alta (fig. 14): Se sitúa sobre la anterior y consta de dos entradas, una que es la abertura original y otra desarrollada en el fondo de la cavidad al erosionarse y desaparecer parte de la pared. Tiene el aspecto de un gran arco, puesto que la bóveda está prácticamente arrasada. Al igual que las anteriores, el espesor rocoso del techo es mínimo, dado que la superficie topográfica se encuentra inmediatamente encima del techo de la cavidad.

Cueva del Tesoro o de la Paja: Es de reducidas dimensiones y sección elíptica muy aplanada, con el suelo horizontal, y que en su conjunto tiene un aspecto subesférico achatado. Se desarrolla en las areniscas descritas, observándose en su extremo más interior una serie de superficies de laminación con abundantes óxidos de hierro. El techo presenta manchas amarillas debidas a tinciones y a alteraciones de la roca a partir de núcleos de diferente composición. 
Cueva de los Pilones: Es un abrigo rocoso cuyo techo está constituido por las Areniscas del Aljibe, mientras que la cavidad se desarrolla en los materiales margosos infrayacentes. Su sección es triangular y su boca corresponde a un plano de fractura vertical, que constituye el borde de la visera, apareciendo en el suelo grandes bloques de arenisca producidos por desplome de aquélla. Los materiales son similares a los descritos. En sus cercanías existen unas charcas o pilones naturales, con agua durante todo el año, que se originan por la surgencia en superficie de un manantial de aguas subterráneas.

Cueva de Palomas 1: Las Cuevas de Palomas se encuentran situadas en un crestón de areniscas silíceas denominado Los Barracones (fig. 13), que constituye el cierre de un pequeño valle fluvial que en algunos puntos presenta fenómenos de endorreísmo, dando lugar a un mal drenaje, con desarrollo de zonas encharcadas. La Cueva de Palomas 1 (fig. 15) se encuentra enclavada en los materiales silíceos de la Formación Areniscas del Aljibe, que en este punto se presentan constituyendo un flanco monoclinal inclinado hacia el E. Estas areniscas aparecen estratificadas en banco métricos, que internamente presentan numerosas estructuras sedimentarias. En algunos puntos éstas aparecen más destacadas, al encontrarse los planos de laminación interna remarcados por una fina lámina de óxidos de hierro. La cavidad atraviesa completamente el macizo rocoso, dando lugar a dos aberturas, una al SW y otra al NE, que se encuentran unidas por una gran sala de sección elíptica, desarrollada en un plano inclinado hacia el W-SW, en cuyas paredes laterales se encuentran las representaciones pintadas. El techo de la cavidad (fig. 16) aparece completamente corroído, presentando numerosos alveolos de tamaños centi y decimétricos, observándose también una alteración de la roca por formación de escamas. El suelo es irregular, fuertemente inclinado, con bloques y sedimentos detríticos de variada glanumetría y carácter autóctono, dado que corresponden a arenas silíceas producto de la alteración in situ de las areniscas siliceas o grandes bloques desprendidos del techo y de las viseras. Estos sedimentos están parcialmente desmantelados, constatándose esta erosión en las paredes de la cavidad, en donde se aprecian marcas de presencia de sedimentos a unos $30 \mathrm{~cm}$ por encima de la superficie del suelo actual. Destaca entre estos depósitos un gran bloque de arenisca de dimensiones métricas que se encuentra actualmente en proceso de intensa alteración, acumulándose en su entorno las correspondientes arenas siliceas.

Cueva de Palomas 2: Esta cavidad está situada a escasos metros al NW de la anterior, accediéndose a ella por una superficie inclinada desarrollada a favor de las diaclasas que cortan el flanco monoclinal en que se presentan las Areniscas del Aljibe en la zona. Esta superficie ter- 
mina por debajo del acceso principal del abrigo en un fuerte escarpe que da inicio a una pared vertical. La cavidad consta de una entrada principal situada hacia el $W$ y de otra pequeña abertura o ventana que se encuentra en su extremo más oriental. Ésta es fruto de la erosión y desmantelamiento del delgado techo que la cavidad presenta en su zona interior. El abrigo es de sección elíptica y su desarrollo en plano inclinado hacia el $W$, con una morfología tubular. El techo se encuentra alterado con numerosos alveolos circulares centi y decimétricos, mientras que el suelo es liso y carece de sedimentos.

Gran Abrigo de Bacinete: Los Abrigos de Bacinete (fig. 17) están situados en la ladera suroccidental del Cerro del Piruétano, accidente geográfico que conforma el extremo oriental de la Sierra del Niño, estando este cerro separado de ella por un collado de dirección NS denominado Puerto de Bacinete. Los abrigos y cavidades que forman este conjunto rupestre están desarrollados sobre las rocas silíceas de las Areniscas del Aljibe, que en este punto presentan una morfología de grandes tafonis, integrada por bloques prismáticos de grandes dimensiones separados por estrechos corredores longitudinales. La morfología de los bloques está determinada por planos de debilidad como son los de estratificación, que generan superficies de despegue subhorizontales, y los de fracturación, responsables de las superficies verticales, donde se sitúan los corredores. Los bloques presentan líneas de corrosión muy marcadas formando una retícula, en función de la intersección de los planos de la estratificación y de la fracturación con la superficie de los mismos. En determinados bloques existe una corrosión preferencial en la zona basal próxima al suelo que da lugar a abrigos rocosos de superficie cóncava, como es el caso del llamado Gran Abrigo de Bacinete. En la superficie del abrigo se observan áreas en donde la roca se encuentra en proceso de degradación por alteración química, mientras que en otros puntos aparece la superficie tapizada por líquenes y por nidos y otras estructuras orgánicas generadas por insectos.

Abrigo de Bacinete 5: También existen cavidades rocosas casi cerradas, como este lugar, que se encuentra limitado por las paredes de dos bloques, uno de los cuales, con la base parcialmente corroída, se apoya sobre el otro, dando lugar a una pequeña cavidad de perímetro subcircular.

\section{Estudios analiticos: petrografia}

Realizamos el estudio al microscopio petrográfico a partir de las láminas delgadas obtenidas de ocho muestras de areniscas tomadas duran- 
te las campañas de trabajo de campo, que corresponden a las siguientes cavidades:

\begin{tabular}{ccc} 
Muestra & Cavidad & Material \\
\hline T.F.1 & Cueva del Tajo de las Figuras & Arenisca \\
T.F.2 & Cueva del Arco & Arenisca \\
T.F.3 & Cueva Cimera o de los Cochinos & Arenisca \\
T.F.4 & Cueva de los Pilones & Arenisca \\
T.F.5 & Cueva del Arco & Arenisca con Ox. Fe. \\
P.1 & Cueva de Palomas 1 & Arenisca \\
P.2 & Cueva de Palomas 2 & Arenisca \\
B & Gran Abrigo de Bacinete & Arenisca
\end{tabular}

En general, las muestras estudiadas corresponden en su totalidad a areniscas de similares características, cuyos rasgos petrográficos más relevantes son los que se relacionan a continuación.

En cuanto a la composición textural, estas areniscas están constituidas por arenas de dos poblaciones granulométricas bien definidas. Una corresponde al esqueleto y comprende granos gruesos y medios bien redondeados de alta esfericidad. La otra, correspondiente a la matriz, está formada por granos de arenas finas, muy finas y limos, muy angulosos de baja esfericidad. Algunas muestras presentan un tamaño de grano más grueso (T.F.3, T.F.4) o una mayor homogeneidad en torno a tamaños de arenas medias y finas de baja esfericidad y mayor angulosidad (P.1).

La matriz rellena los espacios intergranulares del esqueleto por lo que el empaquetamiento es compacto, excepto en algunas muestras (T.F.5) que están constituidas mayoritariamente por arenas finas, muy angulosas, con un empaquetamiento más abierto.

El mineral principal es el cuarzo, apareciendo de manera accesoria la biotita, que se presenta en láminas finas y de gran longitud en la totalidad de las muestras y minerales del grupo de los inosilicatos en algunas (T.F.2). También se observan zonas muy puntuales con sericita. En algunas muestras (T.F.3) aparecen granos de arena de mayor tamaño constituidos por fragmentos de rocas silíceas metamórficas.

La cementación es silicea, observándose en algunas muestras (T.F.4, T.F.5) una cementación por óxidos de hierro que afecta a las areniscas sin que exista una discontinuidad textural ni estructural entre las zonas de ambos cementos. Los óxidos de hierro aparecen en ocasiones de forma puntual (P.1). 
El aspecto es masivo, sin observarse ningún tipo de ordenamiento interno, a excepción de una tendencia granocreciente en la muestra T.F.2.

En todas las muestras estudiadas no hemos observado indicios de alteración, a excepción de los rasgos de sericitización que pueden responder a la alteración de feldespatos, en cualquier caso de forma muy puntual y que no afecta a la integridad de la roca estudiada.

\section{Estudios analíticos: geoquimica}

En las proximidades de la Cueva del Arco tomamos una muestra de arenisca cementada con óxidos de hierro, de una zona muy puntual, con aspecto subesférico. Los resultados del análisis por plasma y por gravimetria efectuado son los siguientes:

\begin{tabular}{ccccccc} 
Muestra & $\mathrm{Cu} \%$ & $\mathrm{Fe} \%$ & $\mathrm{Zn} \mathrm{ppm}$ & $\mathrm{Pb} \%$ & As ppm & $\mathrm{SiO}_{2} \%$ \\
\hline T.F.5 & 0,011 & 15 & 60 & 0,001 & 20 & 76,51
\end{tabular}

Como se observa, el componente no metálico fundamental es la sílice $\left(\mathrm{SiO}_{2}\right)$, mientras que entre los elementos metálicos destaca la presencia de hierro ( $\mathrm{Fe}$ ), apreciándose pequeñas cantidades de cobre y plomo, así como la presencia mínima de zinc y arsenio (en partes por millón o ppm).

Dado que en las Areniscas del Aljibe se observan cementaciones parciales por óxidos de hierro, la presencia de éste en concentraciones mayores, como la de la muestra, unido a otros elementos metálicos, puede atribuirse a la existencia de cantos blandos de naturaleza limosa, que sirven de núcleos para la precipitación de los óxidos metálicos cementantes.

\section{Conclusiones}

Desde el punto de vista geológico, las cavidades que componen los conjuntos rupestres del Tajo de las Figuras, Abrigos de Bacinete y Cuevas de Palomas se caracterizan por desarrollarse en los materiales silíceos de la Formación Areniscas del Aljibe, que constituyen prácticamente los principales relieves de la zona estudiada.

Geomorfológicamente las cavidades rocosas donde aparecen las manifestaciones artísticas corresponden a tafonis de diferente magnitud, que en algunos casos evolucionan en auténticos abrigos rocosos. Estas formas erosivas tienen su origen en la acción abrasiva del viento, que 
cargado de partículas ataca las areniscas, disgregándolas en las zonas de mayor exposición. En algunos casos a la erosión eólica hay que añadir la acción edáfica, dado que los suelos desarrollados en contacto con las superficies rocosas verticales modeladas por el viento producen una alteración de dichas superficies, las cuales al desaparecer la cubierta edáfica se disgregan con gran facilidad acrecentándose el acavernamiento del tafoni. Esto se observa en los Abrigos de Bacinete. En otras ocasiones la proximidad de los techos de las cavidades a la superficie topográfica condiciona la existencia de arcos, dobles entradas, pequeños orificios, debidos en la mayoría de los casos a la erosión eólica. Un buen ejemplo lo constituyen la Cueva del Arco o las dos Cuevas de Palomas descritas aquí. En el caso de la Cueva de los Pilones, su origen se debe al desplome de un gran bloque en una zona de contacto entre las areniscas y las margas infrayacentes donde existe además un mal drenaje. La erosión de dichas margas condujo al descalce de las viseras de areniscas, cayendo un gran bloque de éstas sobre los materiales margosos.

Entre las diferentes formas de alteración de las superficies rocosas podemos destacar las siguientes: la formación de alveolos por acción eólica, el desarrollo de escamas a favor de los planos de laminación de las areniscas, la abrasión eólica (figs. 18 y 30) y la alteración química. Otras formas de alteración tienen su origen en la acción de organismos vegetales y animales, destacando, en este sentido, la nidificación tanto de insectos como de aves en la mayoría de las cavidades, como analizaremos seguidamente.

\section{ESTUDIO BOTÁNICO}

En 1988 se describieron las comunidades de criptógamas que se encuentran en las Cuevas del Tajo de las Figuras, del Arco y Cimera o de los Cochinos.

Cueva del Tajo de las Figuras (fig. 19): Debido a la morfología y profundidad de esta cavidad los liquenes no se desarrollan en su interior, por falta de luz. No obstante, se observan algunos recubrimientos de color grisáceo en estado seco, que se oscurecen cuando están húmedos. Estos se encuentran en el techo y ocupan superficies de entre 20 y $150 \mathrm{~cm}^{2}$. Posiblemente son cianoficeas del género Phormidium (figs. 20 y 21). La humedad que generan los vientos de Levante durante el invierno puede crear unas condiciones ambientales adecuadas para el desarrollo de Phormidium, que suele formar pequeñas incrustaciones de carbonato cálcico, que en este caso tienen unos $0,10 \mathrm{~mm}$ de grosor. No 
puede descartarse la hipótesis de que estos talos sean hongos epilíticos o endolíticos, que mineralizarian el substrato rocoso.

Cueva del Arco (fig. 19): Es la estación más expuesta a la luz, al viento y a la lluvia. Su substrato y cavidades son muy irregulares, por lo que las comunidades de criptógamas presentan gran diversidad, dependiendo, principalmente, de la cantidad de luz recibida (fig. 22).

Cueva Cimera o de los Cochinos (fig. 19): Estamos ante un abrigo más abierto que la Cueva del Tajo de las Figuras, más iluminado, sobre todo en su parte inferior. En este yacimiento representa un papel importante su orientación, al Norte, que favorece el desarrollo de una comunidad liquénica dominada por Dirina repanda en el fondo de la cavidad. En este lugar se realizó un transecto vertical para cuantificar la densidad de talos por unidad de superficie y el gradiente de especies hacia zonas menos iluminadas, como el techo. Los recuentos, sobre $100 \mathrm{~cm}^{2}$, se efectuaron cada $15 \mathrm{~cm}$, hasta $140 \mathrm{~cm}$ de altura, desde el suelo (fig. 23). Dirina repanda se extiende desde 0 hasta $120 \mathrm{~cm}$ y Verrucaria predomina desde 100 a $140 \mathrm{~cm}$. La densidad del talo es muy elevada (Dirina repanda: $1,25 \mathrm{talo} / \mathrm{cm}^{2}$; Verrucaria: $0,32 \mathrm{talo} / \mathrm{cm}^{2}$ ) y en la parte baja el recubrimiento llega al $100 \%$. En la entrada, en la parte Oeste, la comunidad de Dirina repanda crece con Roccella phycopsis, Caloplaca, Lecanora y diversos briófitos. En el exterior, sobre grandes bloques de piedra, predomina la comunidad de Pertusaria rupicola, juntamente con otras especies del género Pertusaria, Candelariella vitellina, Anaptychia fusca, Caloplaca ferruginea, Parmelia stenophylla y el musgo Pterogonium ornithopodioides.

La conservación de las pinturas de la Cueva del Arco y Cimera o de los Cochinos es difícil, ya que las características morfológicas de la primera y la orientación de la segunda favorecen el desarrollo de comunidades liquénicas. La actividad corrosiva de estos organismos es evidente y debajo de su talo las pinturas ya no existen. La Cueva del Tajo de las Figuras, también debido a sus características morfológicas, no favorece la aparición de criptógamas, a pesar de existir algunas, con una incidencia relativa y efectos a largo plazo. Este estudio se realizó de forma puramente descriptiva. Para profundizar en la investigación de las comunidades de criptógamas que nos ocupan se precisaba de análisis al microscopio, con el fin de determinar con exactitud las especies y estudiar su actividad degradante. La recolección de muestras, sin embargo, nos pareció imprudente y arriesgada.

Con el fin de observar el impacto que produce la actividad fisiológica de las comunidades de liquenes sobre las superficies rocosas se clasificaron y procesaron algunas muestras obtenidas en 1988 en abrigos 
alejados de los yacimientos con representaciones artísticas, pero que estaban ocupados por las mismas comunidades liquénicas, para ser analizadas con el microscopio electrónico de rastreo (scanning) del Servei de Microscòpia Electrònica de la Universitat de Barcelona. Esta técnica permite estudiar no sólo la micromorfología externa de un espécimen determinado, sino también su ultraestructura interna, mediante cortes semifinos longitudinales y transversales de la propia muestra (figs. 24 y 25). En 1990 planteamos un trabajo experimental con el fin de profundizar en el impacto que produce la actividad fisiológica de las comunidades de liquenes sobre las superficies rocosas, con las mismas especies, pero no necesariamente con muestras de la zona que nos ocupa, partiendo de los líquenes identificados en las cavidades objeto de estudio en el trabajo de campo de 1988. Continuariamos así, por ejemplo, las investigaciones sobre la ecofisiología de Dirina y los análisis de sustancias liquénicas. La falta de presupuesto impidió, sin embargo, avanzar en este sentido, que creemos interesante de cara a un futuro más o menos próximo.

\section{ESTUDIO ZOOLÓGICO}

Realizamos dos campañas de trabajo de campo, en 1988 y 1989. A partir de la primera, en la que se llevó a cabo un muestreo en el Conjunto rupestre del Tajo de las Figuras, y basándonos en los datos y el material recogidos, establecimos las directrices a seguir en el estudio de la fauna de las cavidades y su incidencia en la degradación de las manifestaciones rupestres.

Observamos la presencia en las Cuevas del Tajo de las Figuras, del Arco y Cimera o de los Cochinos, de agrupaciones de nidos de avispas terreras, que llegan, en algunos casos, a incrustrarse en el substrato rocoso. El caso más aparente lo encontramos en la Cueva del Tajo de las Figuras, en la que los nidos construidos llegan a ocupar de un 10 a un $15 \%$ de su superficie, disponiéndose principalmente en el techo (fig. 6).

La recolección de ejemplares para su identificación y estudio nos ha llevado al siguiente diagnóstico: Orden Himenoptera, Familia Sphecidae, Género Sceliphron (fig. 26).

En estos mismos abrigos existen colonias de nidos de aves, son de barro y recubren grandes superficies de los techos. Su situación y la actividad de los pájaros en época de cría pueden deteriorar los paneles pintados y grabados en cierta medida. En la Cueva del Tajo de las Figuras corresponden a una colonia de aviones comunes (Delichon urbica) (fig. 27). 
En 1989 el trabajo de campo se dirigió hacia la continuación del muestreo en el Conjunto rupestre del Tajo de las Figuras y en las Cuevas de los Ladrones o Pretinas, que tuvo los siguientes objetivos: elaboración de croquis -mediante fotografías, dibujos, gráficos, anotaciones...- de las superficies de las cavidades ocupadas por nidos; recolección de los insectos que construyen estos nidos o los ocupan secundariamente y de los que se encuentran en otras partes de las estaciones observadas; y estudio de los restos dejados por vertebrados superiores (egagrópilas, excrementos...) en estos lugares. Para ello se tomaron datos cuantitativos área afectada, tamaño de las construcciones y nivel de asociación-y cualitativos -estado y grado de integración de los nidos-. Las observaciones in situ mostraron que las superficies de los abrigos están afectadas mayoritariamente por nidos de avispas terreras (Sceliphron $\mathrm{sp}$ ). Hay que señalar que actualmente la actividad de la especie ha disminuido sensiblemente, comenzando a ser escasa su presencia. No obstante, algunos de estos nidos están ocupados por otras especies de insectos, que los utilizan para su refugio y puesta, aprovechando la protección que les ofrecen para realizar la metamorfosis, y también por arácnidos (fig. 28). En alguno de los abrigos de las Cuevas de los Ladrones o Pretinas y en la Cueva Cimera o de los Cochinos se detectó la presencia de construcciones de otra especie de heminóptero, son de barro, esféricas, de menor volumen y localizadas aisladamente, sin tendencia a la agregación. Además de los nidos de avión común (Delichon urbica), cerrados y con agujero de entrada en la parte superior, fuertemente agregados, formando densas colonias que tienden a ocupar los techos de los abrigos en sus zonas más externas, como es característico, vimos también nidos de otra ave, chochín (Troglodytes troglodytes), en la Cueva de los Pilones.

Las egagrópilas halladas son de gran tamaño y corresponden a rapaces nocturnas. Han sido encontradas de manera más o menos irregular en los suelos de los abrigos rocosos, pero nunca formando cúmulos importantes que denoten la nidificación u ocupación continuada. Su composición la constituyen pelaje y huesos de micromamiferos en su mayor parte. Por el tipo de hábitat y los restos encontrados podemos determinar la presencia de búho real (Bubo bubo, Orden Strigiformes, Familia Strigidae), especie sedentaria que ocupa el mismo territorio todo el año, cuyo hábitat preferido son los riscos y promontorios rocosos de zonas boscosas y que suele establecer su territorio en las zonas periféricas de las sierras, englobando así parte de sierra y prados o cultivos, en donde tiene una buena área de caza. Sus presas son principalmente mamíferos, desde micromamíferos hasta conejos y liebres. Nidifica al abrigo de grandes rocas o troncos. El nido es una simple oquedad escarbada en el suelo, con restos de egagrópilas y huesos. Algunos restos de egagrópi- 
las también podrian ser de cárabo común (Strix aluco). Esta especie habita principalmente en zonas boscosas mediterráneas y puede frecuentar los promontorios rocosos, aunque no tan claramente como el búho real.

Los restos de excrementos de aves (avión común, búho real...) no parecen tener una repercusión muy importante, aunque el efecto de todas estas deposiciones puede ser muy erosivo y afectar gravemente ciertas zonas con grabados o pinturas, y llegar a constituir un problema si se produce un aumento de las colonias de avión común o el asentamiento continuado de otras especies, como por ejemplo intentos de nidificación de las rapaces nocturnas. La posibilidad de la presencia de éstas en los abrigos es mayor cuanto más protección les ofrezcan (promontorios rocosos de situación elevada, poca frecuencia de visitas del hombre..., condiciones que cumplen muchos abrigos de la zona que nos ocupa).

Los excrementos de mamíferos carnivoros ${ }^{10}$ no denotan su asentamiento en los abrigos. Todo parece indicar presencias ocasionales (fig. 30) y se trata de pequeños excrementos (roedores) o de mayor tamaño (carnivoros). Hemos identificado los mamíferos que se relacionan. Ratón de campo (Apodemus sylvaticus, Orden Rodentia, Familia Muridae): es típico del bosque mediterráneo, se encuentra en pinares y frecuentemente en lugares con robles y encinas. Come frutos, semillas, insectos y arácnidos. Cuando accede a áreas más abiertas lo encontramos en las cercanias de zonas arboladas y puede ser un visitador esporádico de las cavidades. Zorro (Vulpes vulpes, Orden Carnivora, Familia Canidae): carnívoro de amplia distribución y oportunista, que puede ser también un visitador ocasional de los abrigos. Garduña (Martes foina, Orden Carnivora, Familia Mustelidae): ocupa zonas boscosas variadas, pero siempre mantiene una preferencia por lugares con formaciones rocosas.

\section{BIBLIOGRAFIA}

FontBotÉ, J.M. (1983): «La Cordillera Bética. Zonas internas y unidades adyacentes», Libro Jubilar J. M. Ríos. Geología de España. Instituto Geológico Minero de España, Madrid, págs. 251-343.

FONTBOTE, J.M., y VERA, J.A. (1983): “La Cordillera Bética. Introducción», Libro Jubilar J. M. Rios. Geologia de España. Instituto Geológico Minero de España, Madrid, págs. 205-218.

GavaLA, J. (1916): «Regiones petrolíferas de Andalucía», Boletín del Instituto Geológico Minero de España, 37, Madrid, págs. 33-208.

10 No hemos tenido en cuenta los restos, en algunos casos muy abundantes, creando una gruesa costra, de los animales citados al principio (cabras, ciervos...), cuya presencia continuada es evidente. 
- (1929): “La Geología del Estrecho de Gibraltar", Boletín del Instituto Geológico Minero de España, 51, Madrid, págs. 3-36.

ITGE (1991): Mapa Geológico de España, Escala 1:50.000, Tahivilla, 1.074 (13-47). Instituto Tecnológico Geominero de España, Madrid.

MAS CORNELlȦ, MARTI (1989): "Algunas consideraciones sobre la conservación del arte prehistórico en el Conjunto rupestre del Tajo de las Figuras (Cádiz), XIX Congreso Nacional de Arqueología. Castellón de la Plana, 1987. Il: Arte rupestre y Valle del Ebro, Secretaria General de los Congresos Arqueológicos Nacionales, Zaragoza, págs. 161167.

- (1993): “Proyecto: Las manifestaciones rupestres prehistóricas en la zona gaditana. El arte prehistórico en las sierras del Campo de Gibraltar” (Juan M. Campos Carrasco y Francisco Nocete Calvo, editores): Investigaciones arqueológicas en Andalucia, 1985-1992. Proyectos, Dirección General de Bienes Culturales de la Consejeria de Cultura y Medio Ambiente de la Junta de Andalucía, Huelva, págs. 263-271.

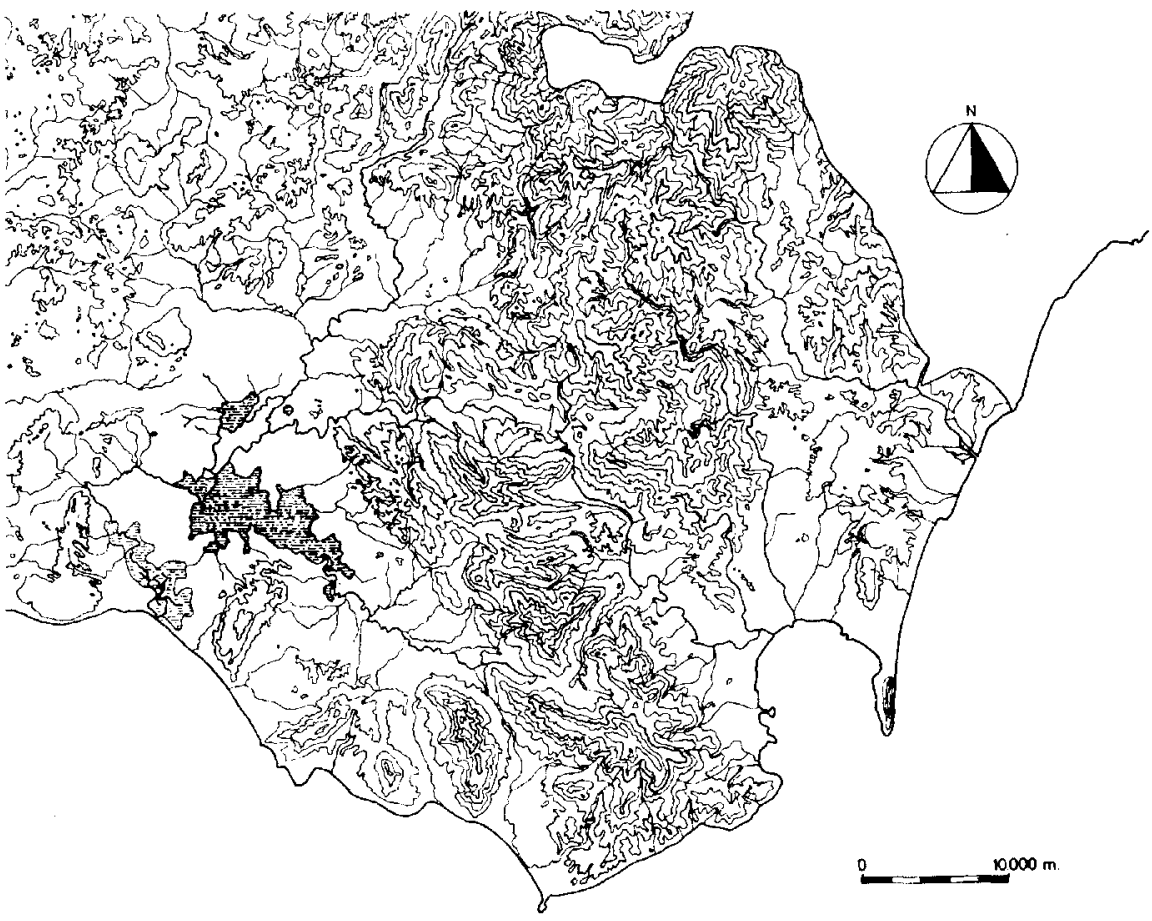

Fig. 1. Reconstrucción de la antigua Laguna de la Janda y las sierras que la bordean por el Este en el Sureste de la provincia de Cádiz (dibujo realizado a partir de la cartografia siguiente: MAPA TOPOGRÁFICO NACIONAL, ESCALA 1:50.000, VEJER DE LA FronteRA (1.073), Dirección General del Instituto Geográfico Nacional, Madrid (segunda edición), 1955; MAPA TOPOGRÁFICO NACIONAL, ESCALA 1:50.000, Las Habas (1.074), Dirección General del instituto Geográfico Nacional, Madrid (segunda edición), 1960; y MAPA PROVINCIAL, ESCALA 1:200.000, CADIZ Y CIUDAD DE CEUTA, Dirección General del Instituto Geográfico Nacional, Madrid (tercera edición), 1988). 


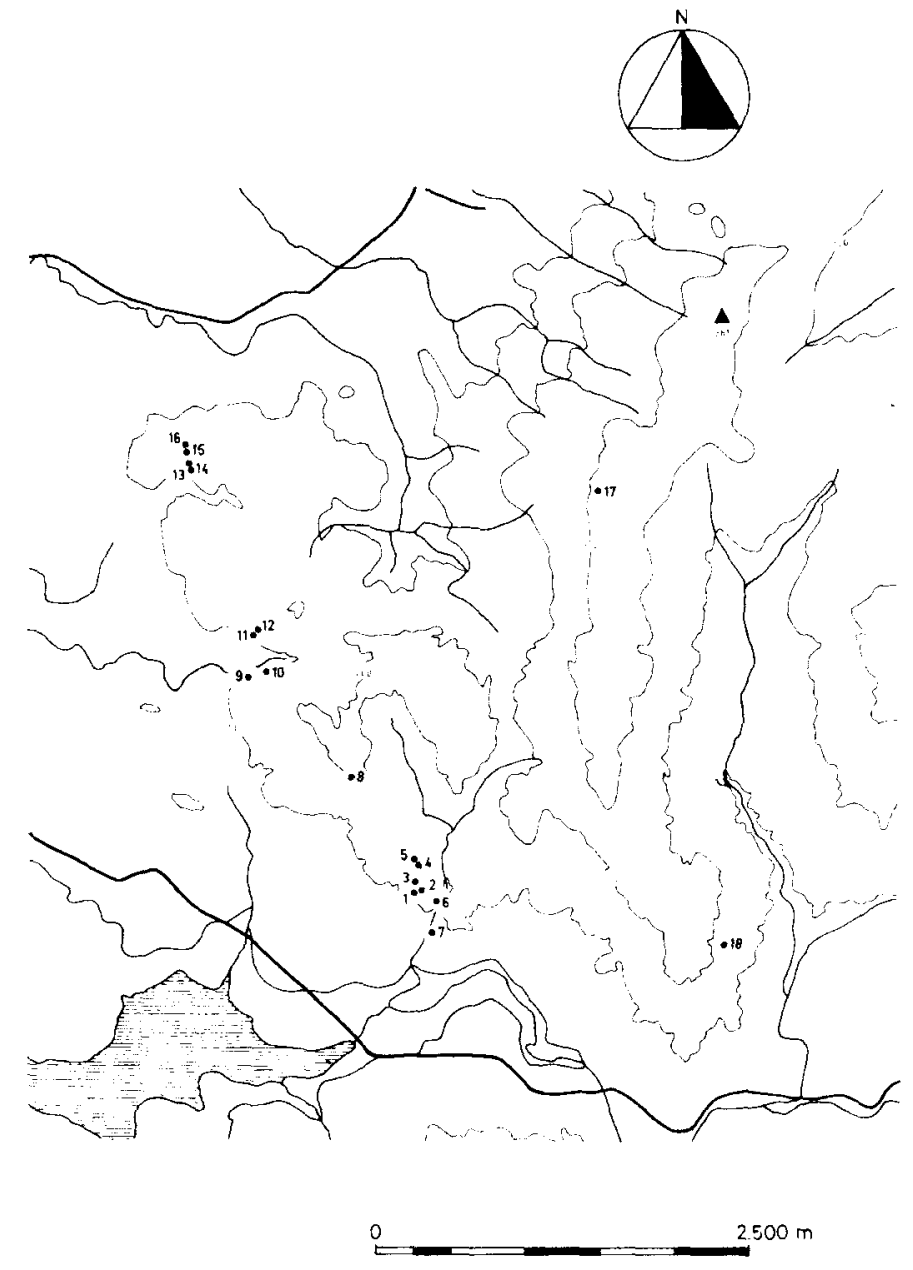

Fig. 2. Mapa de distribución de las cavidades con manifestaciones rupestres de Sierra Momia (1: Cueva del Tajo de las Figuras (situación: x: 254.60, y: 4.022.75 - coordenadas UTM-). 2: Cueva del Arco. 3: Cueva Cimera o de los Cochinos. 4: Cueva Negra. 5: Cueva Alta. 6: Cueva del Tesoro o de la Paja. 7: Cueva de los Pilones (estos siete primeros abrigos rocosos constituyen el Conjunto rupestre del Tajo de las Figuras). 8: Cueva de Luis Lázaro. 9: Cueva del Tajo Amarillo. 10: Cueva Negra de las Pradillas. 11: Cueva de Levante 1. 12: Cueva de Levante 2. 13: Cueva de los Ladrones o Pretina 1. 14: Cueva de los Ladrones o Pretina 2. 15: Cueva de los Ladrones o Pretina 3. 16: Cueva de los Ladrones o Pretina 4. 17: Cueva del Tajo del Cabrito. 18: Cueva del Cañuelo). Elaborado a partir de: MAPA MILITAR DE EsPaña, Escala 1:50.000, TAHIVILLA (1.074), Servicio Geográfico del Ejército, Madrid (sexta edición), 1989; y Mapa Militar de España, Escala 1:50.000, Alcala de los Gazules (1.070), Servicio Geográfico del Ejército, Madrid, 1974. 

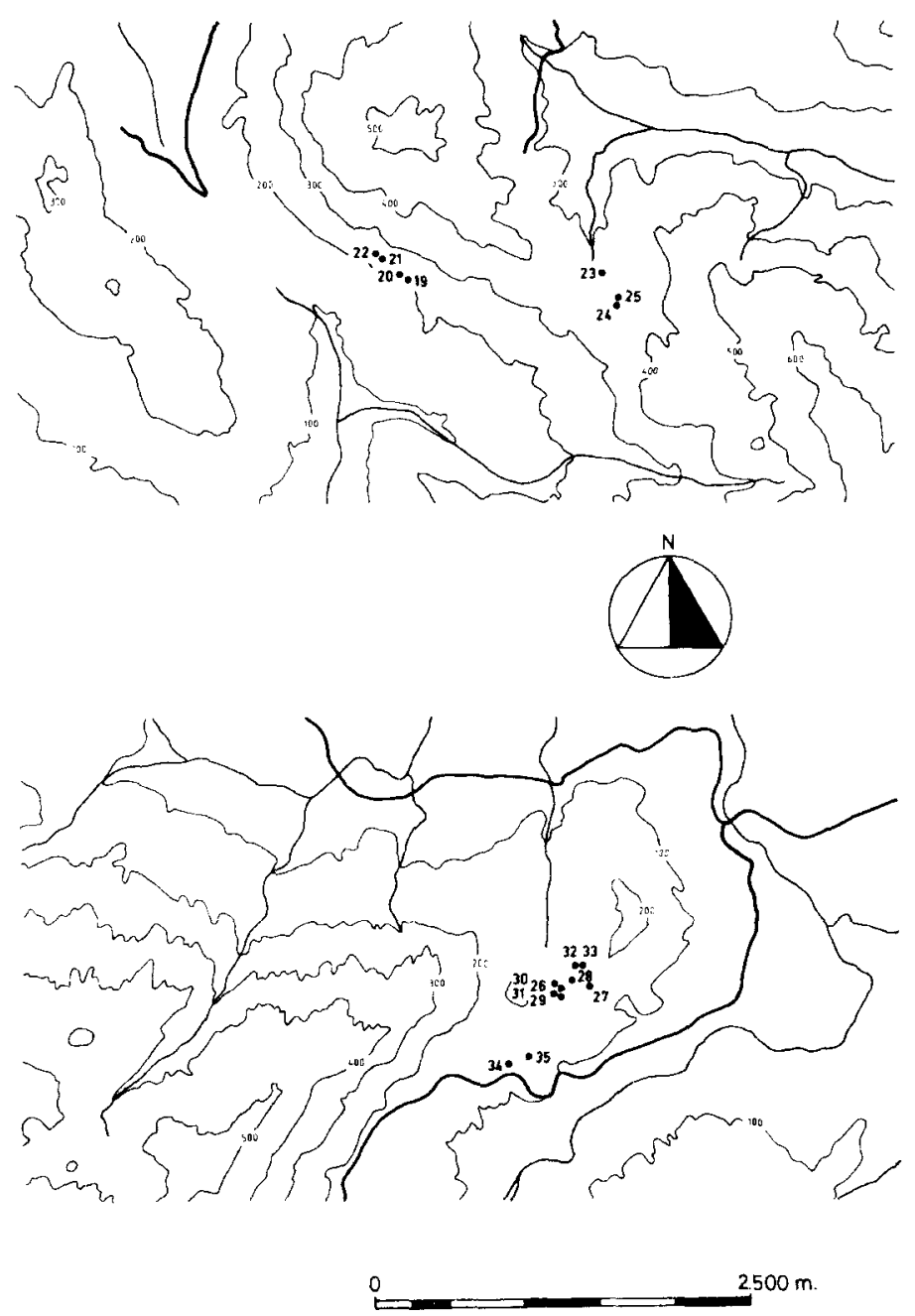

Fig. 3. Mapa de distribución de las cavidades con manifestaciones rupestres de Sierra del Niño (19: Cueva de Palomas 1 (situación: x: 261.00, y: 4.009.30 - coordenadas UTM-). 20: Cuevas de Palomas 2. 21: Cueva de Palomas 3. 22: Cueva de Palomas 4. 23: Cueva del Avellano. 24: Cueva del Obispo 1. 25: Cueva del Obispo 2. 26: Gran Abrigo de Bacinete (situación: x: 270.25 , y: 4.009.00 -coordenadas UTM-). 27: Abrigo de Bacinete 1. 28: Abrigo de Bacinete 2. 29: Abrigo de Bacinete 3. 30: Abrigo de Bacinete 4. 31: Abrigo de Bacinete 5. 32: Abrigo de Bacinete 6. 33: Abrigo de Bacinete 7. 34: Cueva de los Pilones. 35: Peñón de la Cueva). Elaborado a partir del MAPA MilitaR de EsPaña, Escala 1:50.000, Tahivilla (1.074), Servicio Geográfico del Ejército, Madrid (sexta edición), 1989. 
La consenvación del arte rupestre en las sierras del Campo de Gibraltar...

\begin{tabular}{|c|c|c|c|c|c|c|}
\hline & 1987 & 1988 & 1989 & 1990 & 1991 & 1992 \\
\hline Cueva del Tajo de las Figuras .... & 1.288 & 1.555 & 1.633 & 1.798 & 2.169 & 2.478 \\
\hline Cueva del Arco & 1.257 & 1.180 & 1.262 & 1.129 & 1.271 & 1.654 \\
\hline Cueva Cimera o de los Cochinos & 115 & 303 & 254 & 175 & 258 & 200 \\
\hline 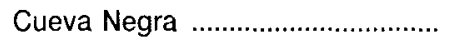 & 8 & 15 & 0 & 0 & 0 & 0 \\
\hline 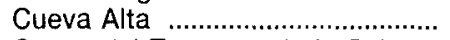 & 0 & 0 & 0 & 0 & 0 & 0 \\
\hline Cueva del Tesoro o de la Paja ... & 15 & 16 & 6 & 7 & 17 & 9 \\
\hline Cueva de los Pilones ....................... & 0 & 0 & 0 & 0 & 0 & 0 \\
\hline
\end{tabular}

Fig. 4. Visitantes del Conjunto rupestre del Tajo de las Figuras entre 1987 y 1992, como puede verse en seis años se ha prácticamente duplicado el número. Muchas de las personas que acuden sólo se interesan por el sitio más conocido, la Cueva del Tajo de las Figuras, aunque algunos no pueden acceder a la cavidad, ya que presenta ciertas dificultades y la sustituyen por la Cueva del Arco. Sólo solicitan visitar la Cueva Cimera o de los Cochinos personas muy interesadas por el arte rupestre, y las Cuevas Negra y del Tesoro o de la Paja únicamente son frecuentadas por un público con un determinado nivel de conocimientos al respecto. Estos datos quizá podrian extrapolarse en cierta forma a los lugares más o menos conocidos y/o frecuentados de la zona gaditana. 


\section{Cueva del Tajo de las Figuras}
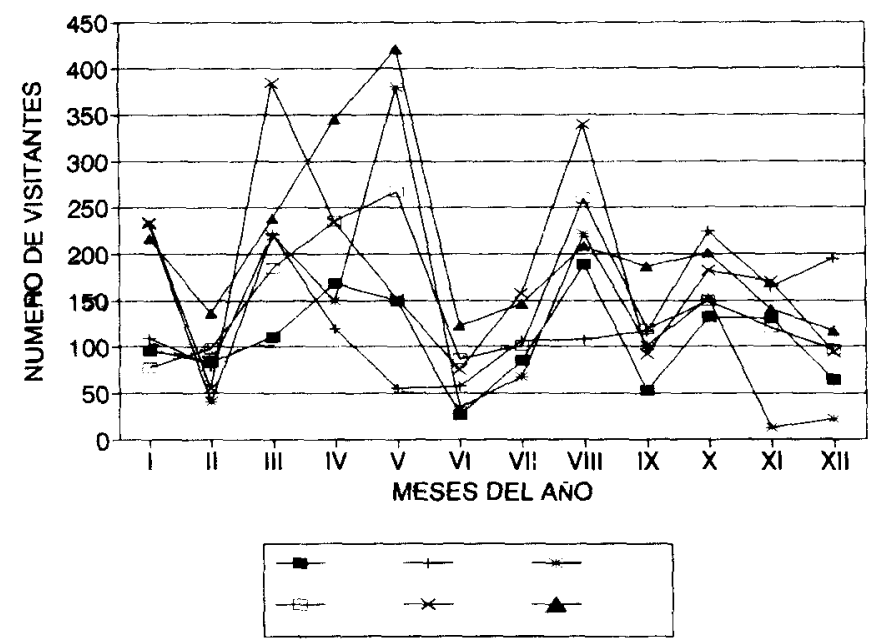

\section{Cueva del Arco}

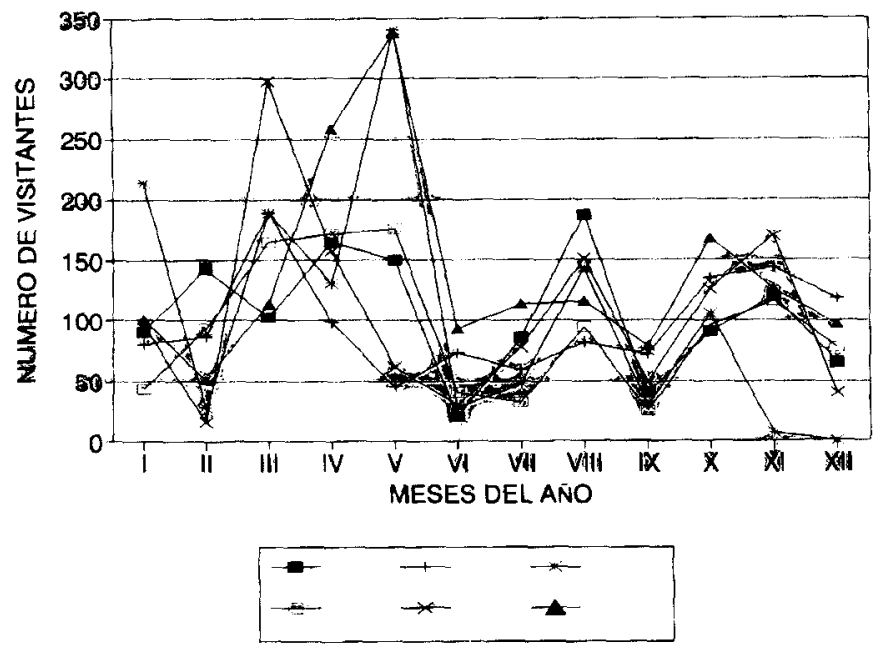

Figs. 5a y 5b. Gráficas de visitantes por mes (1987-1992). Cabe decir que aunque no es un numero excesivo, en comparación con otros yacimientos, es muy irregular, pudiendo llegar a 150 personas en un mismo dia (12 de mayo de 1992), lo que hace que la situación sea dificilmente controlable por parte de un único vigilante y la falta de adecuación del lugar. Como puede observarse, en primavera y a finales del tradicional periodo vacacional (julio y agosto), cuando otras formas de ocio están prácticamente agotadas o ésta constituye una alternativa, son los momentos con una mayor afluencia. 


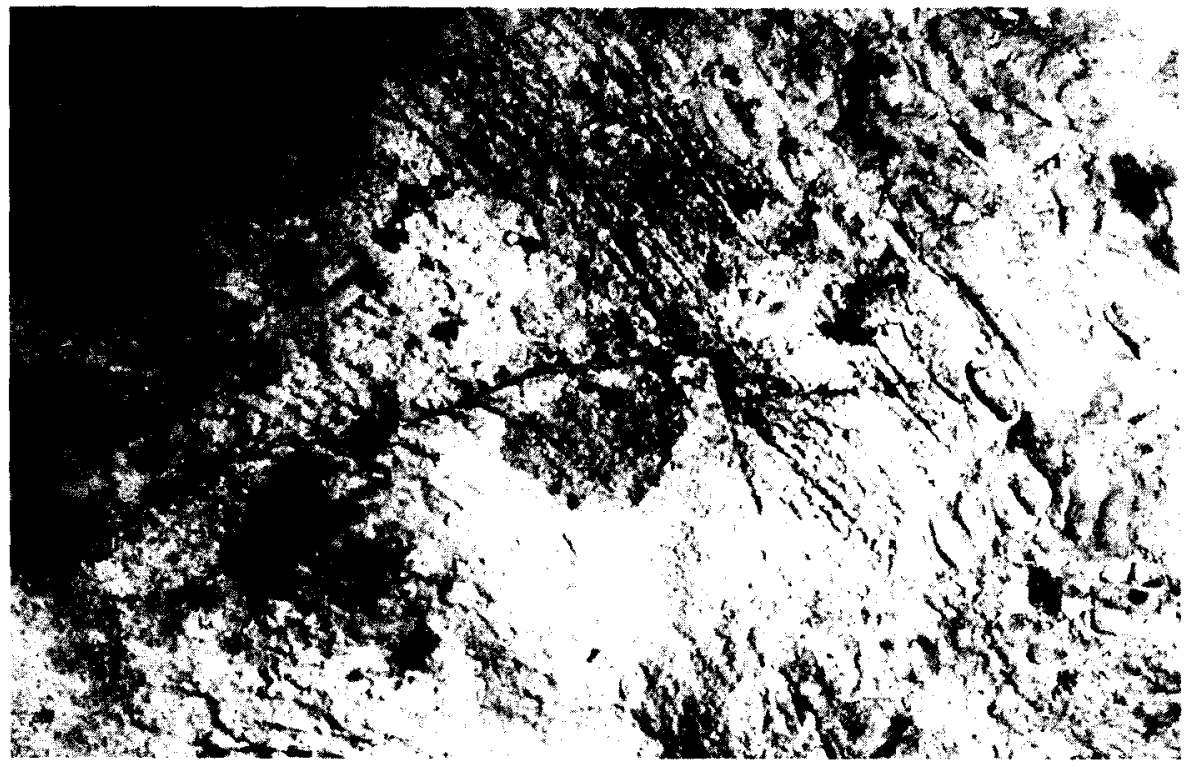

Fig. 6. Nidos de avispas (SCELIPHRON sp) integrados en el soporte rocoso debido a los fenómenos constructivos de tipo biogénico.

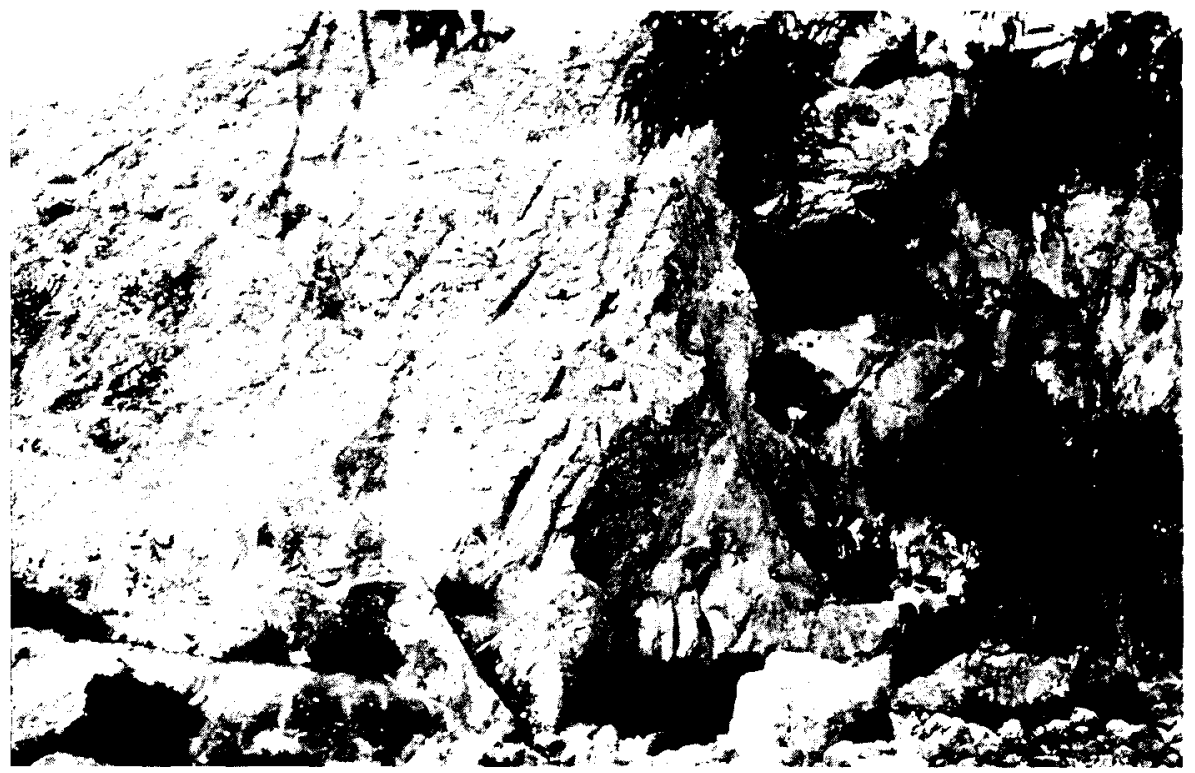

Fig. 7. Exterior de la Cueva del Tajo de las Figuras un dia con cierta afluencia de visitantes. 


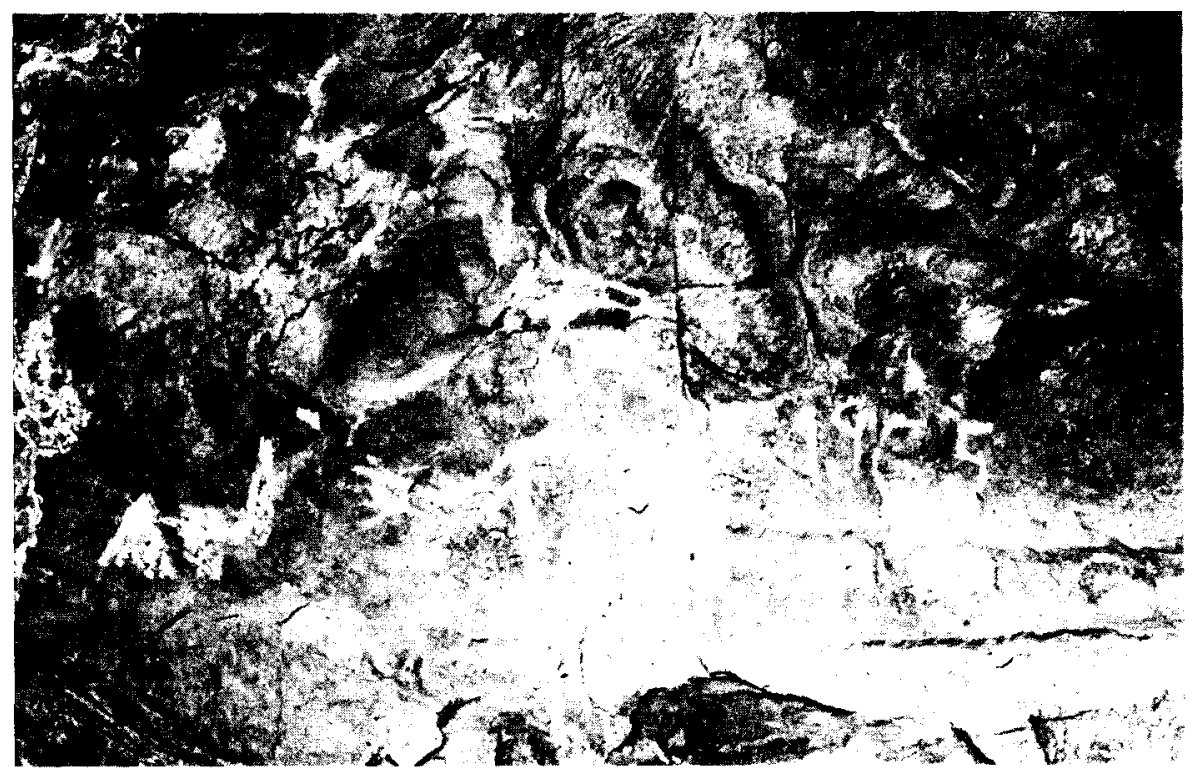

Fig. 8. Pintada de grandes dimensiones sobre un panel con pinturas postpaleoliticas en la Cueva de los Ladrones o Pretina 4.

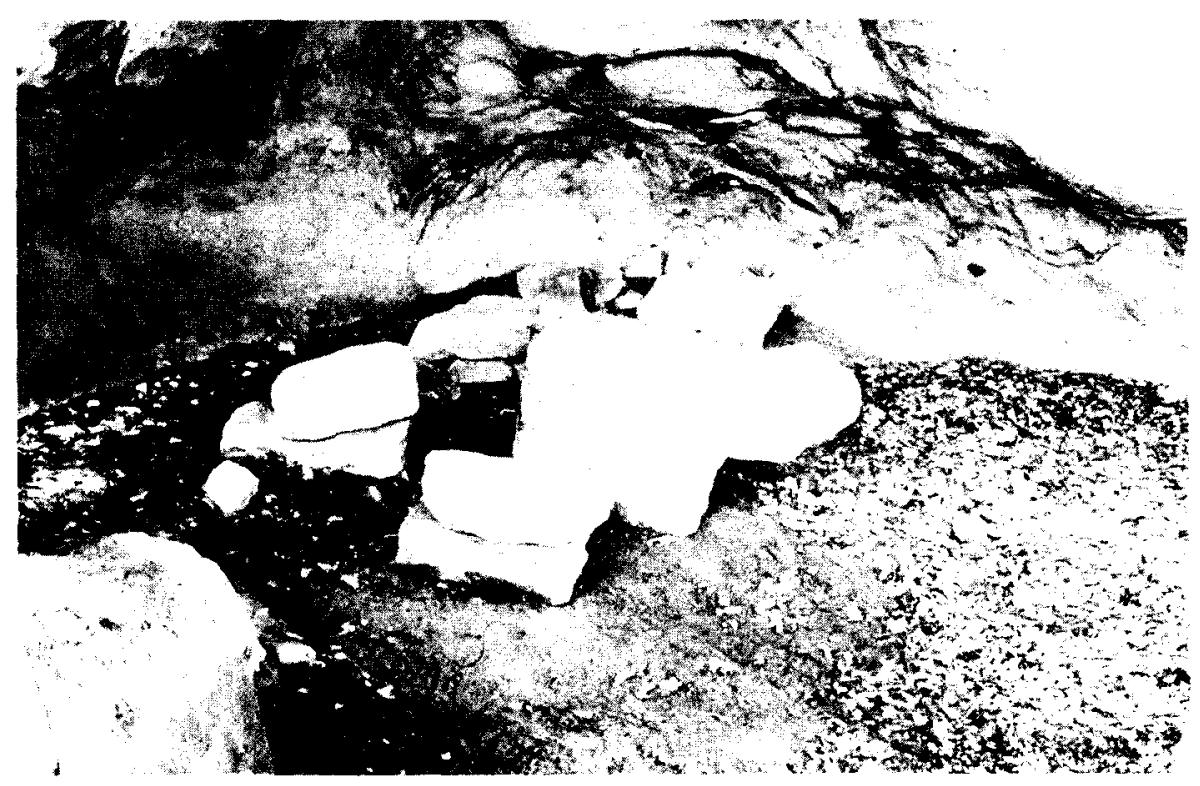

Fig. 9. Interior de la Cueva de Palomas 1. 


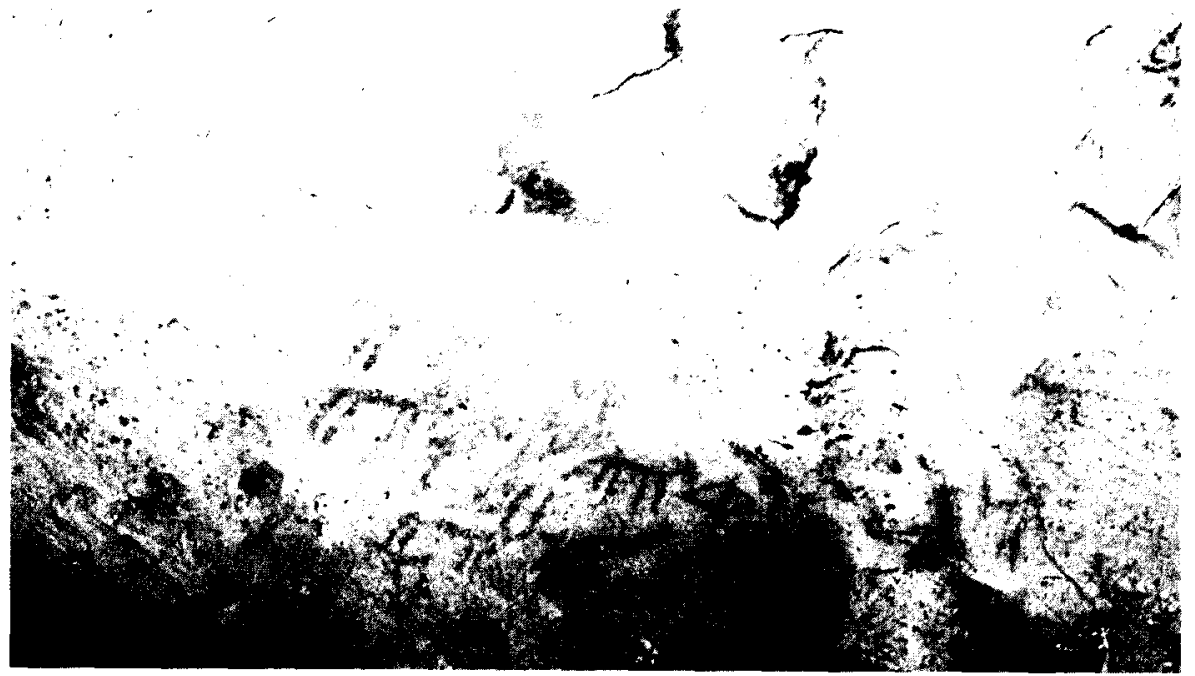

Fig. 10. Estado actual de la roca soporte de las pinturas en el Gran Abrigo de Bacinete.

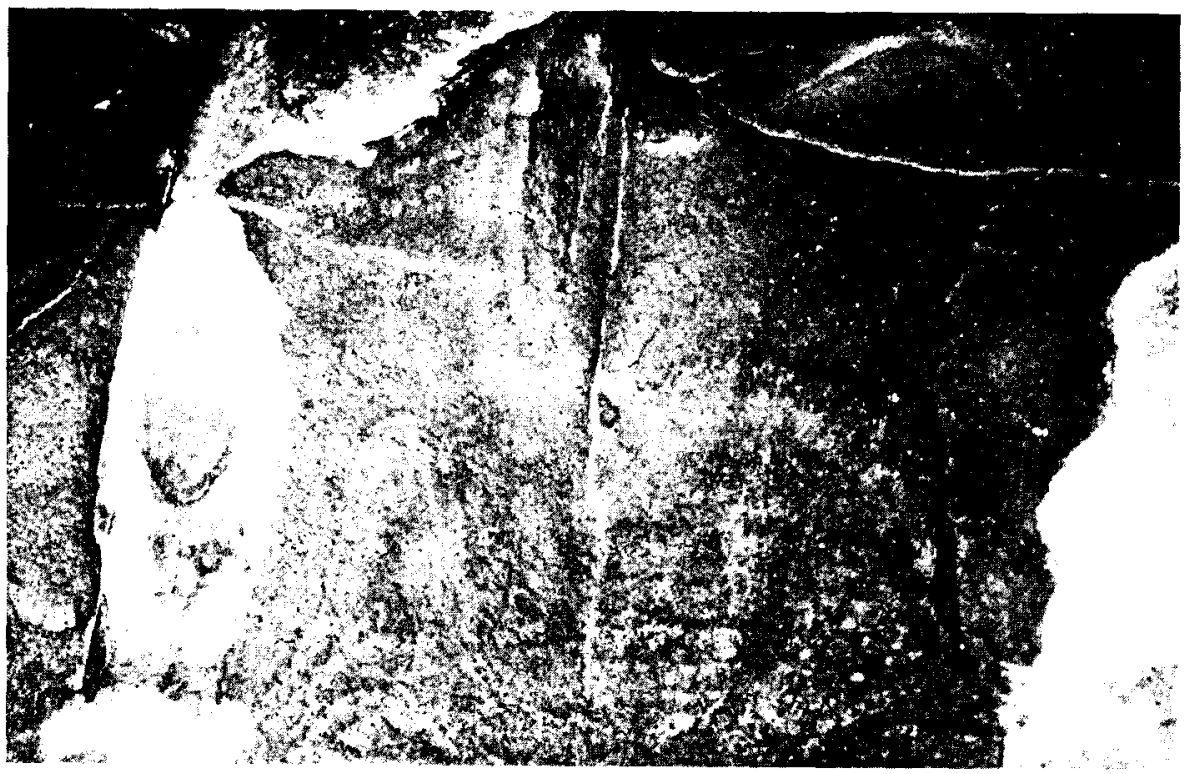

Fig. 11. Efectos de la acción antrópica sobre algunas representaciones del Abrigo de Bacinete 5. 


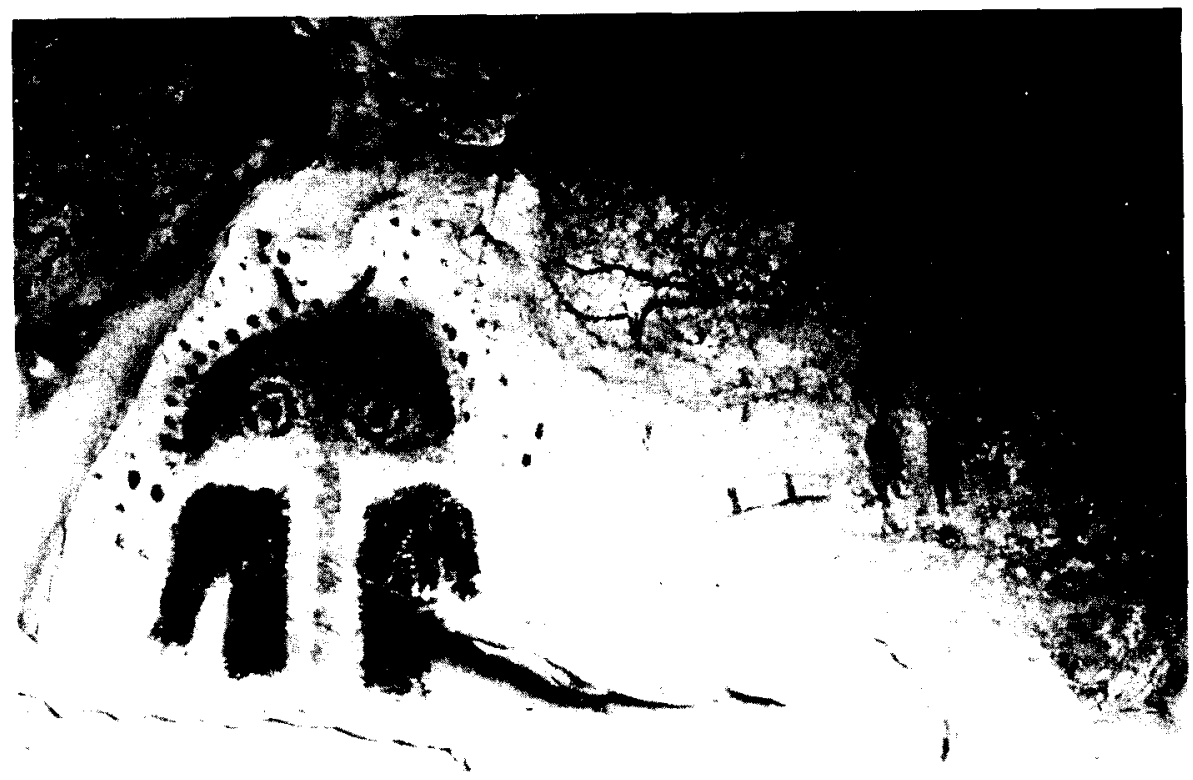

Fig. 12. Pinturas falsas de la Cueva del Curtido.

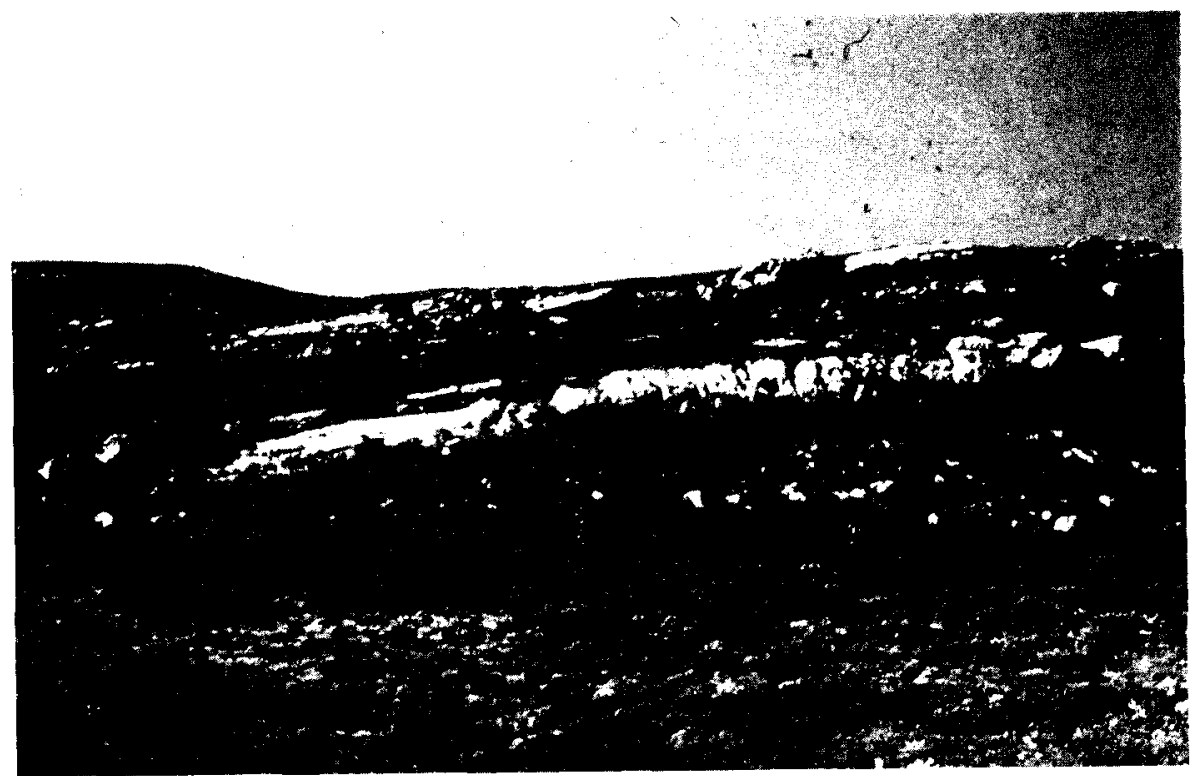

Fig. 13. Vista general del crestón de arenisca silicea en donde se localizan las Cuevas de Palomas. 


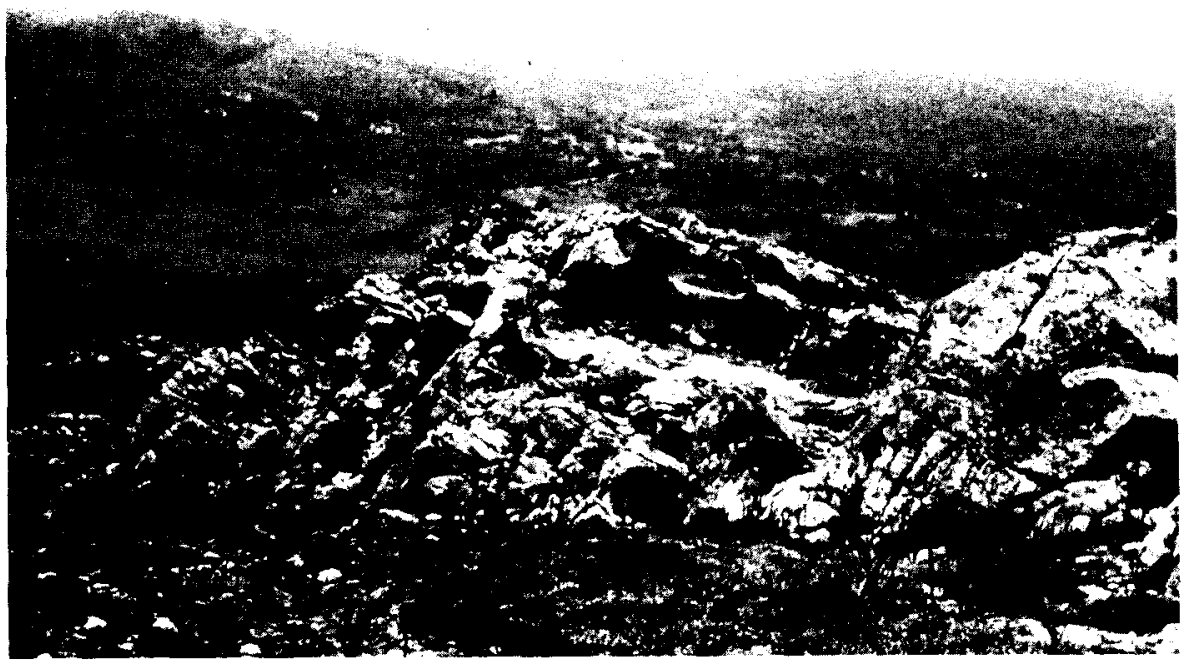

Fig. 14. Exterior de la Cueva Alta. El paisaje se ha visto muy afectado por los incendios de 1993.

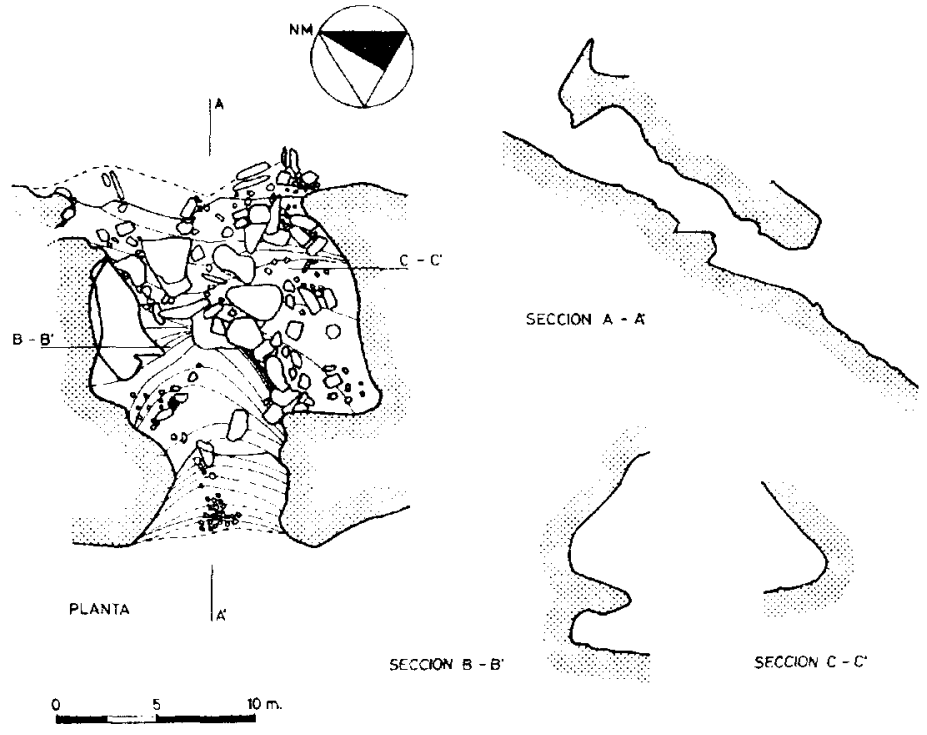

Fig. 15. Plano topográfico de la Cueva de Palomas 1. Pueden observarse los numerosos grandes bloques desprendidos del techo y de las viseras que conforman el irregular suelo de la cavidad. 


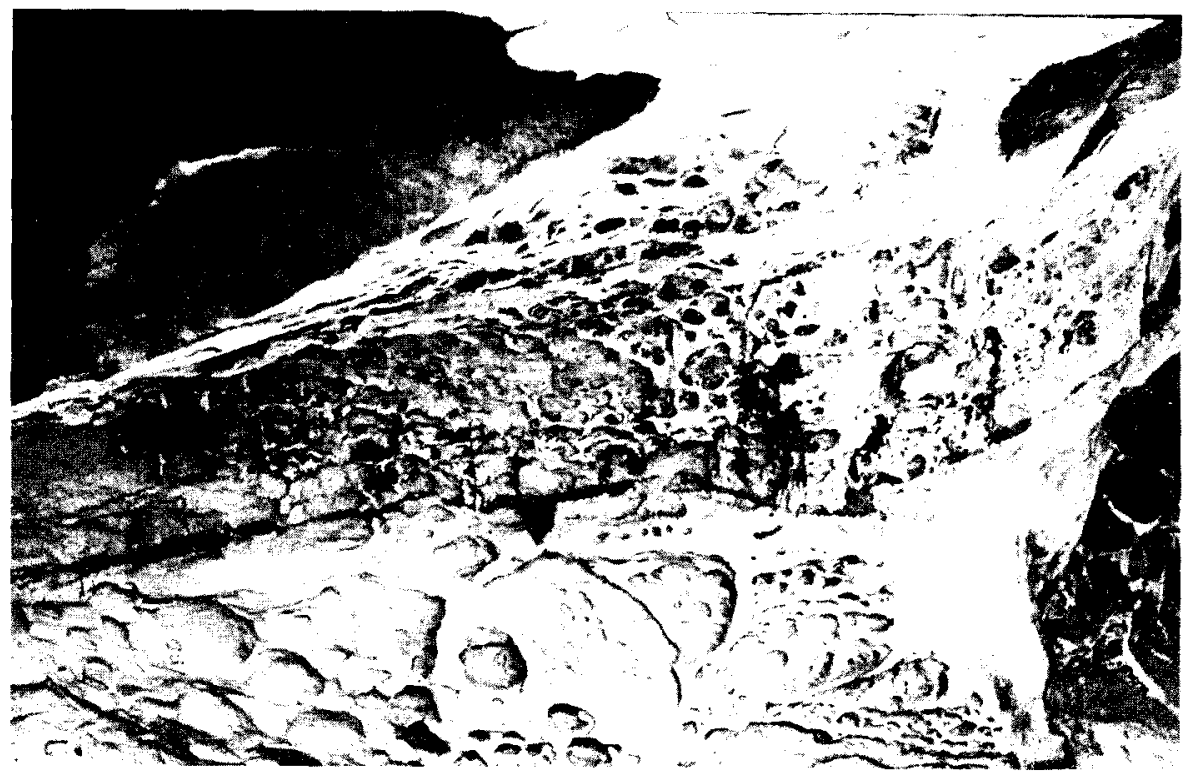

Fig. 16. Detalle del techo de la Cueva de Palomas 1.

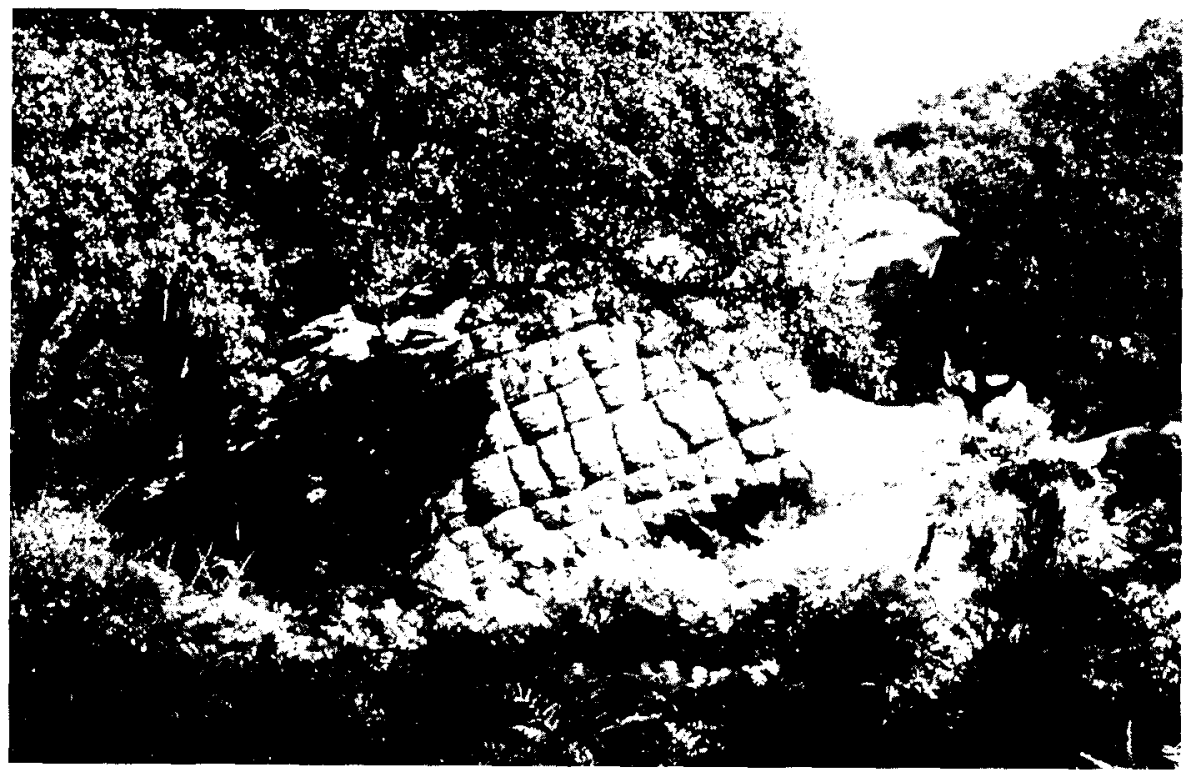

Fig. 17. Vista general del Gran Abrigo de Bacinete, a la derecha se encuentra la entrada del 5. 

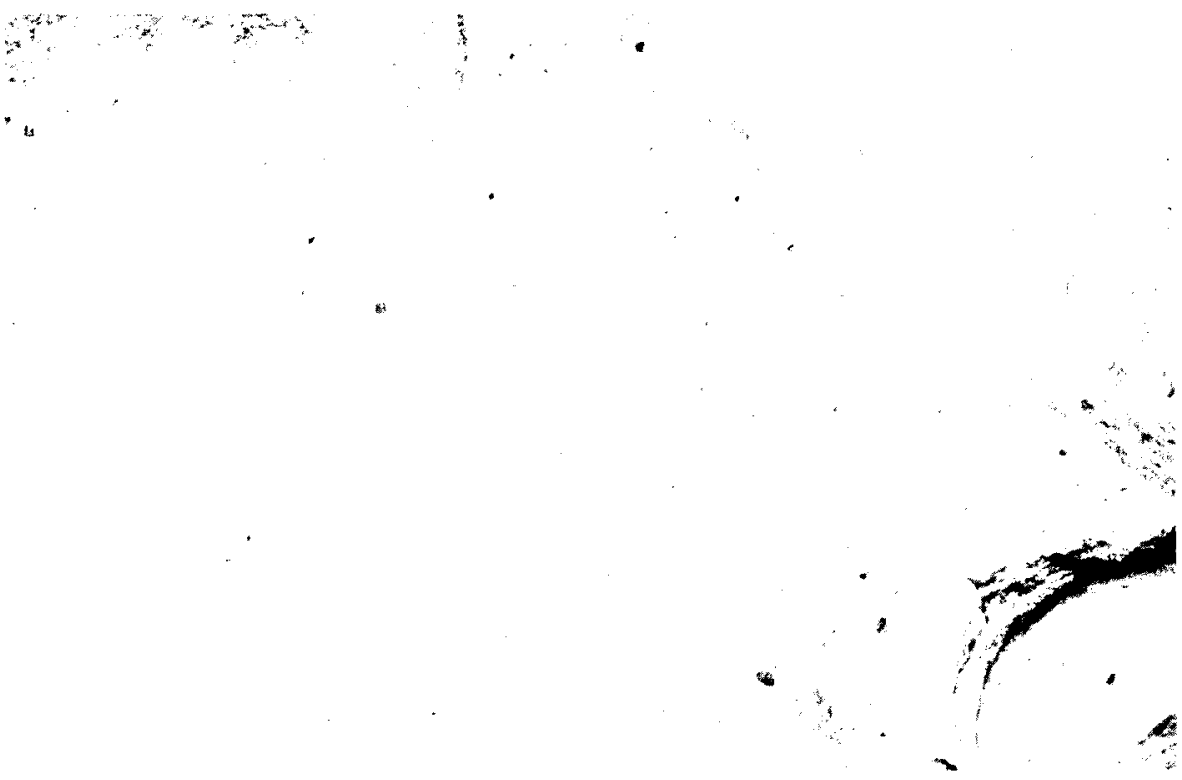

Fig. 18. Restos pictóricos en la Cueva del Tajo del Cabrito. El soporte rocoso está muy afectado por la erosión eólica. 

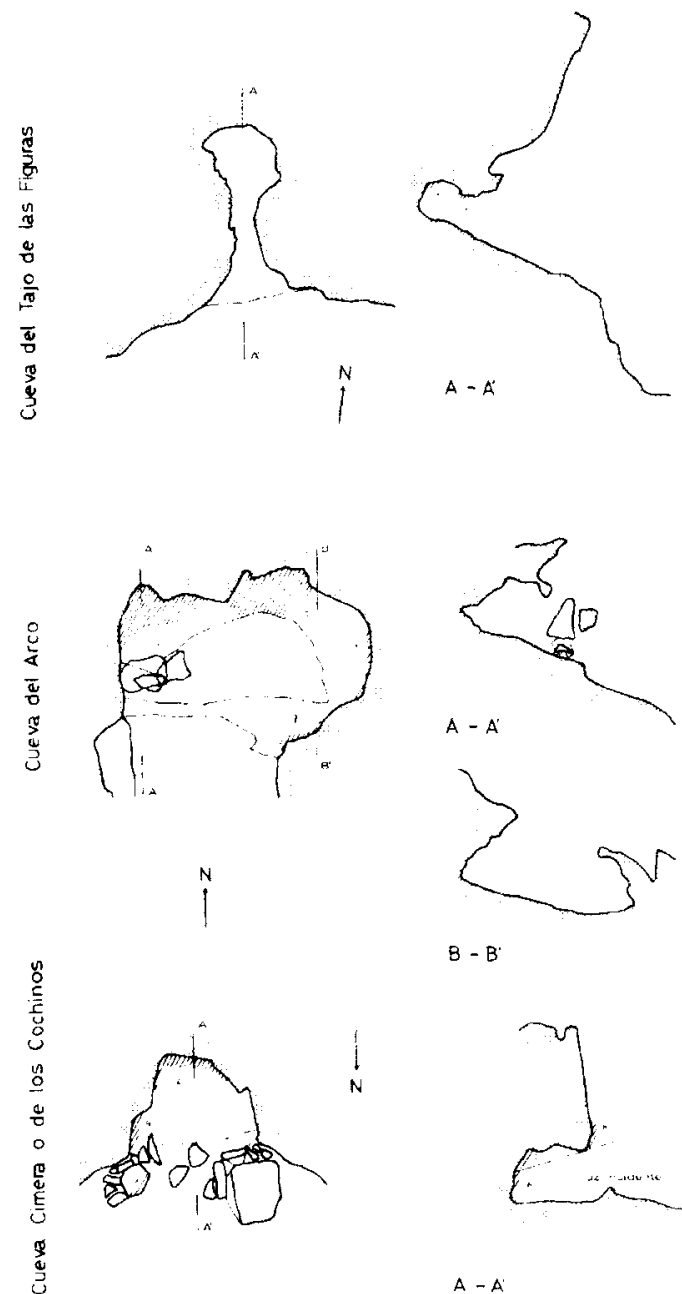

$B-B$

PLANTAS

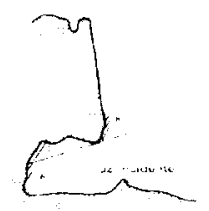

$A-A$

SECCIONES

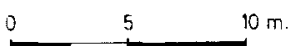

Fig. 19.-Distribución de las comunidades de criptógamas en las Cuevas del Tajo de las Figuras, del Arco y Cimera o de los Cochinos. 1: Comunidad de cianoficeas $u$ hongos epiliticos. 2: Comunidad de DIRINA REPANDA. 3: Briófitos $y$ cianoficeas. 4: Comunidad de DIRINA, ROCCELLA PHYCOPSIS y briófitos. 5: Comunidad de Pertusaria Rupicola. 6: Comunidad de DiRIna y VerRucaria (ver fig. 23). 7: Manchas oscuras de posibles hongos. 8: Comunidad de Ramalina y RHIZOCARPON. 


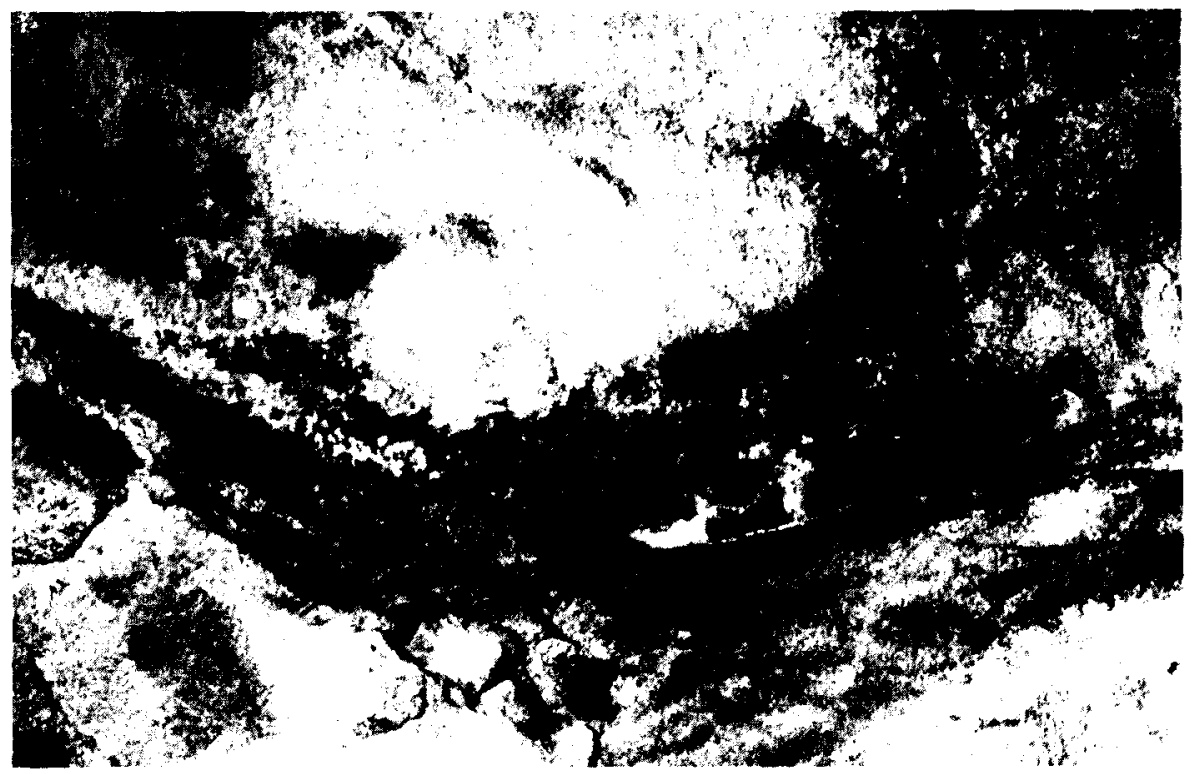

Fig. 20. Talo de cianoficea $u$ hongo epilitico en fisuras de la roca (Cueva del Tajo de las Figuras).

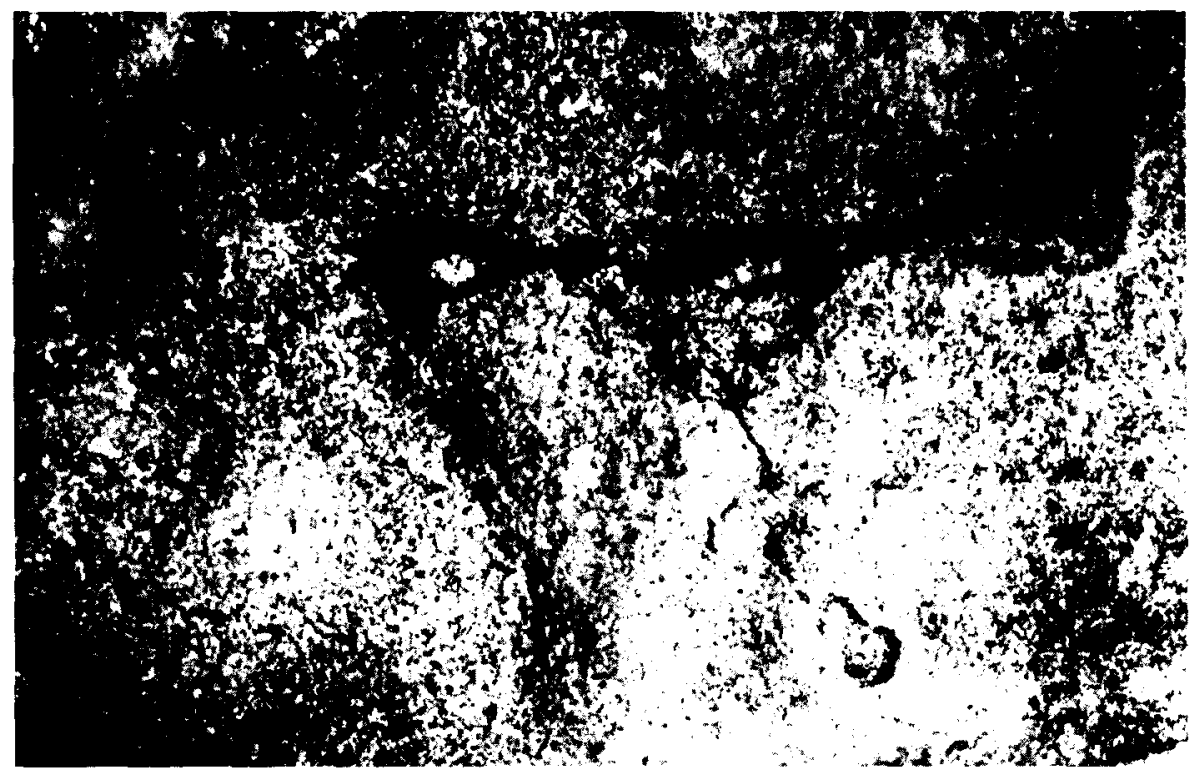

Fig. 21. Detalle del talo de cianoficea $u$ hongo epilitico (fig. 20) sobre una figura pintada. 


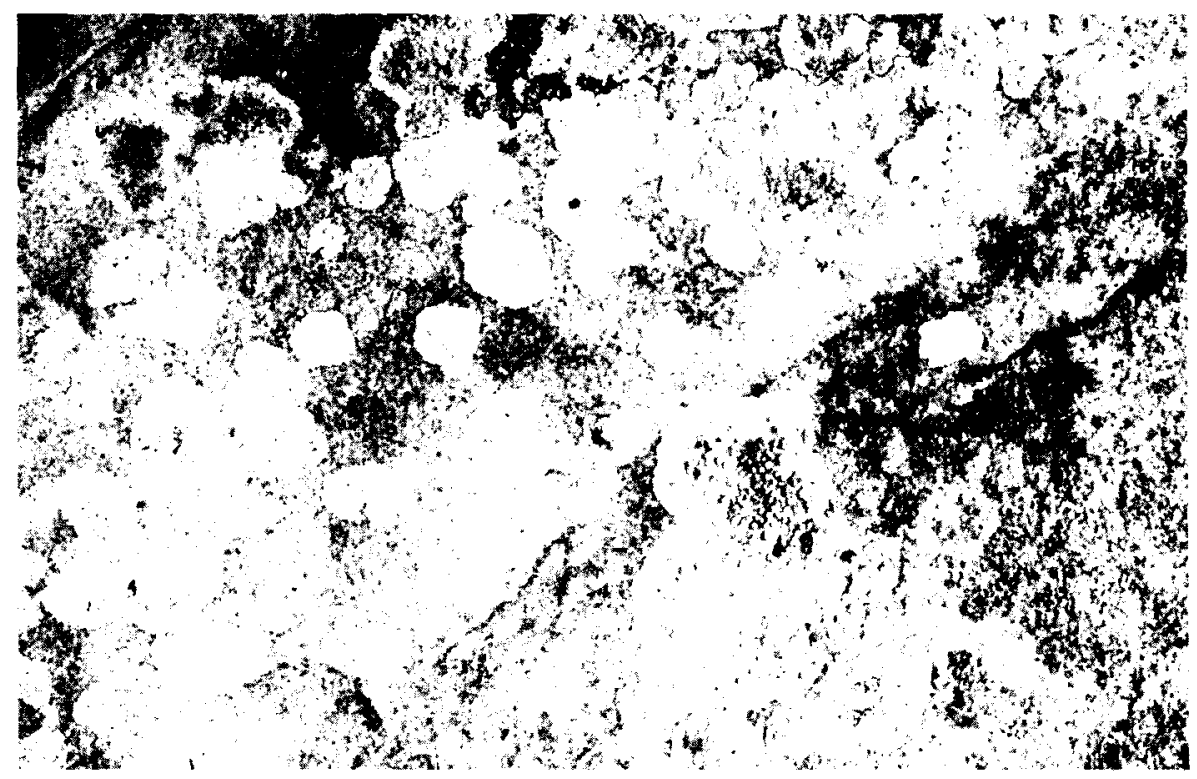

Fig. 22. Detalle del talo de DiRINA REPANDA sobre una superficie pintada en la Cueva del Arco.

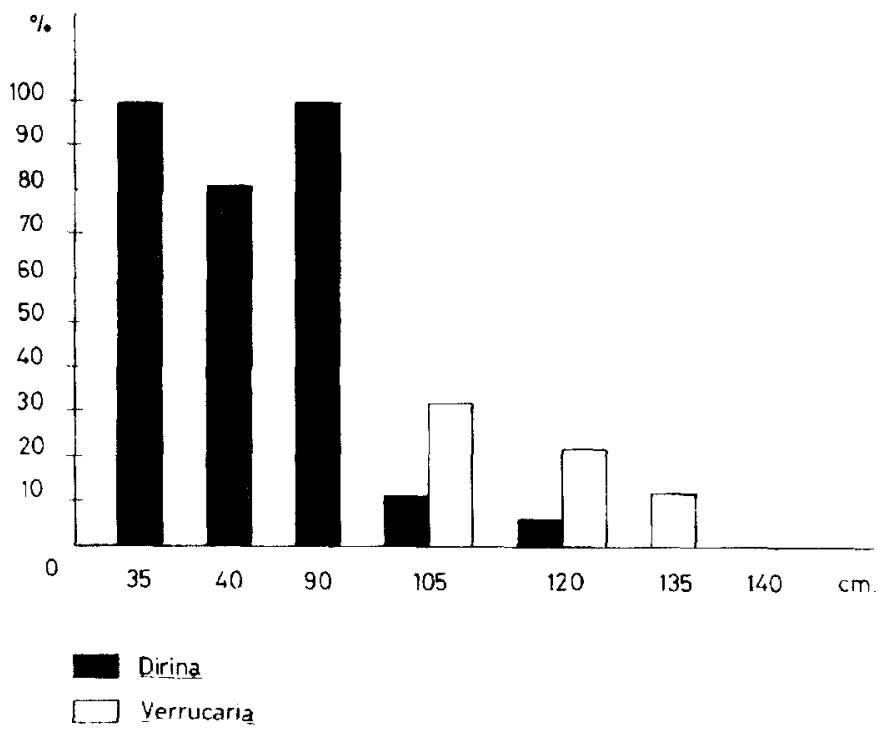

Fig. 23. Frecuencia del talo de DiRINA y VerRucaria en un gradiente vertical del fondo de la Cueva Cimera o de los Cochinos (ver fig. 19: 6). 


\section{La conservación del arte rupestre en las sierras del Campo de Gibraltar...}
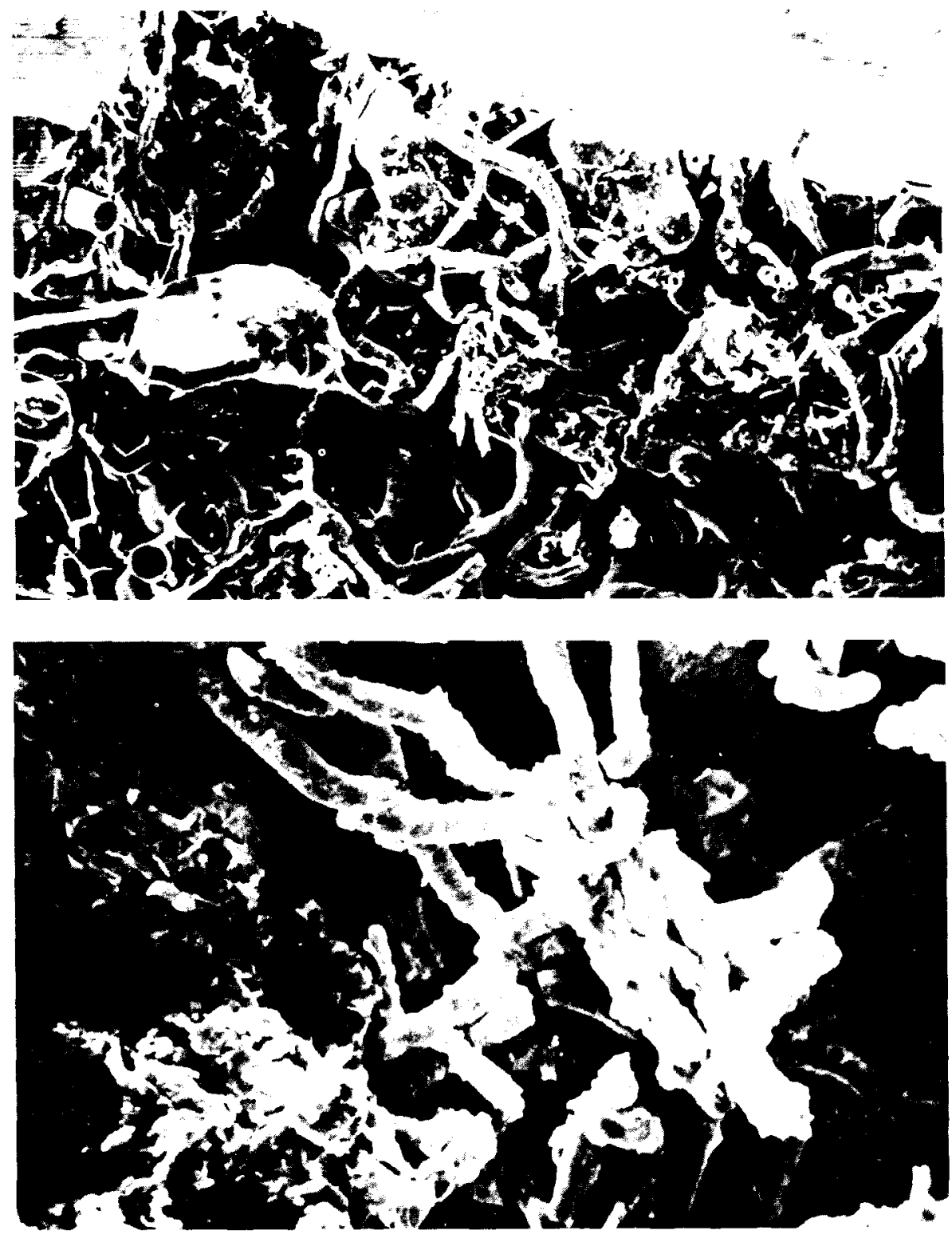

Figs. 24 y 25.-Detalles al microscopio electrónico de rastreo de las hifas de DIRINA SCHISTOSA penetrando en las fisuras de la roca. La escala de la primera indica 50 UM y la de la segunda 20 UM. 


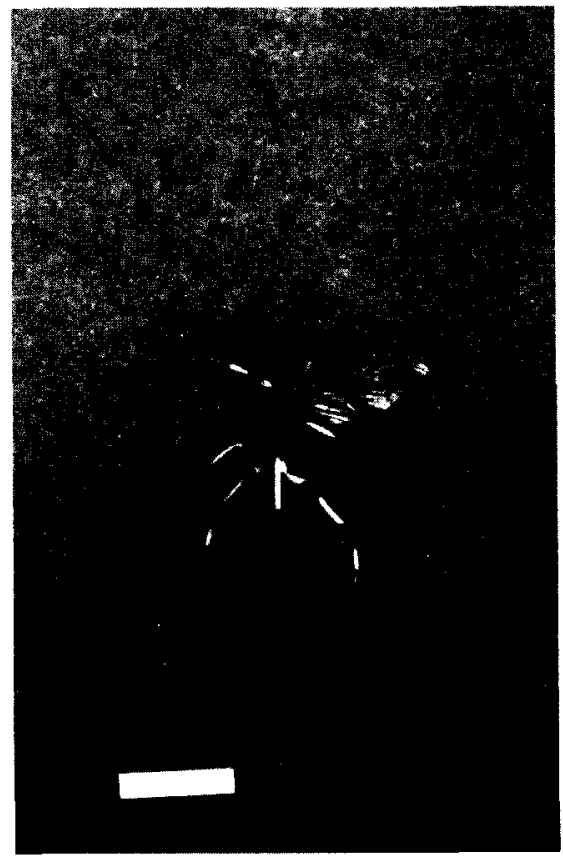

Fig. 26. Ejemplar de avispa terrera (SCELIPHROn sp). Escala: $1 \mathrm{~cm}$.

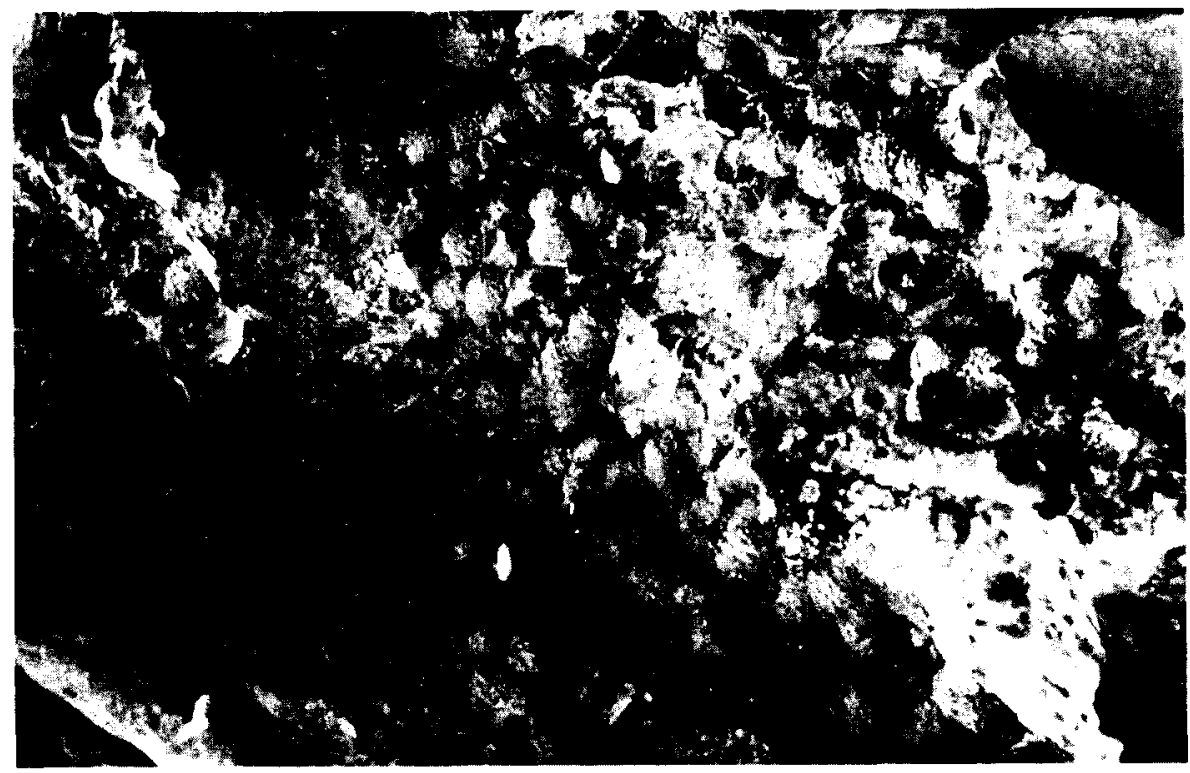

Fig. 27. Nidos de avión común (DELICHON URBICA) en el techo de la Cueva del Tajo de las Figuras. Fotografía tomada en abril de 1986, en época de cria. 


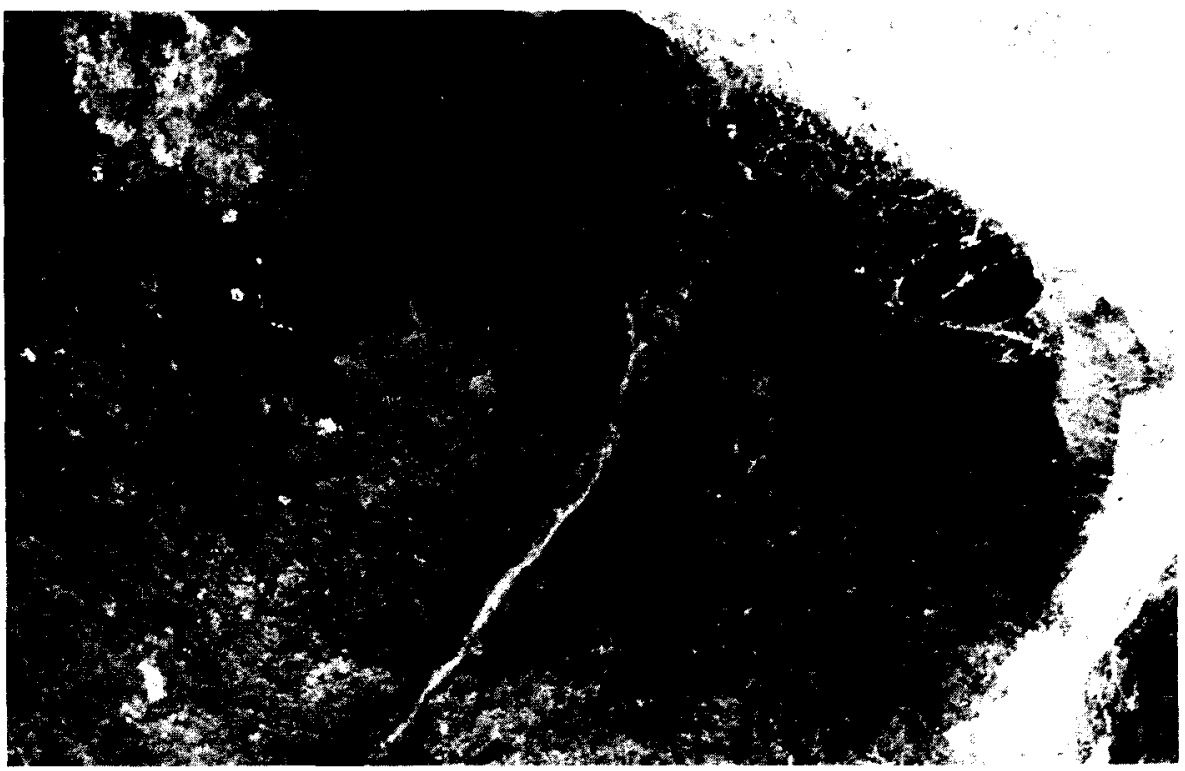

Fig. 28. Restos de nidos de SCELIPHRON sp ocupados secundariamente (Cueva del Tajo de las Figuras).

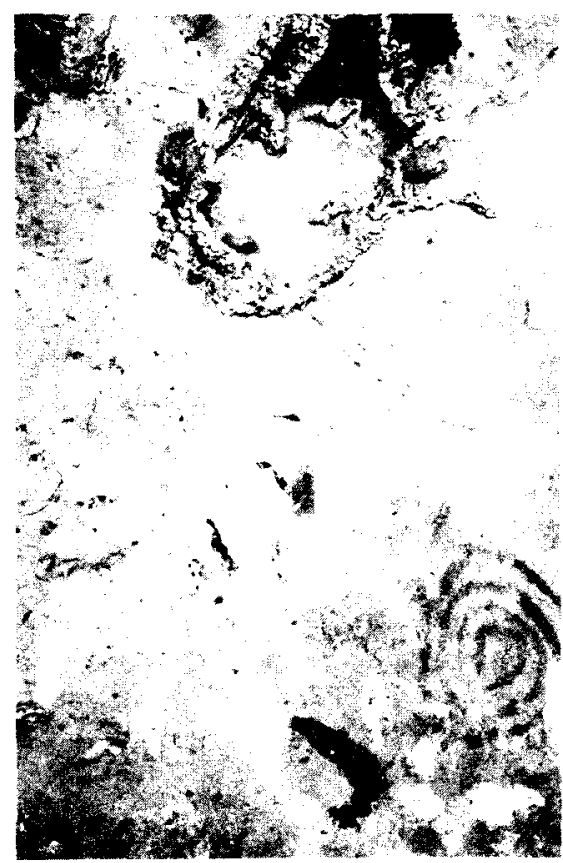

Fig. 29. Algunas figuras de la Cueva de Palomas 2 se han visto afectadas quimicamente debido a la filtración de las sustancias excretadas por las aves dentro de los nidos. 


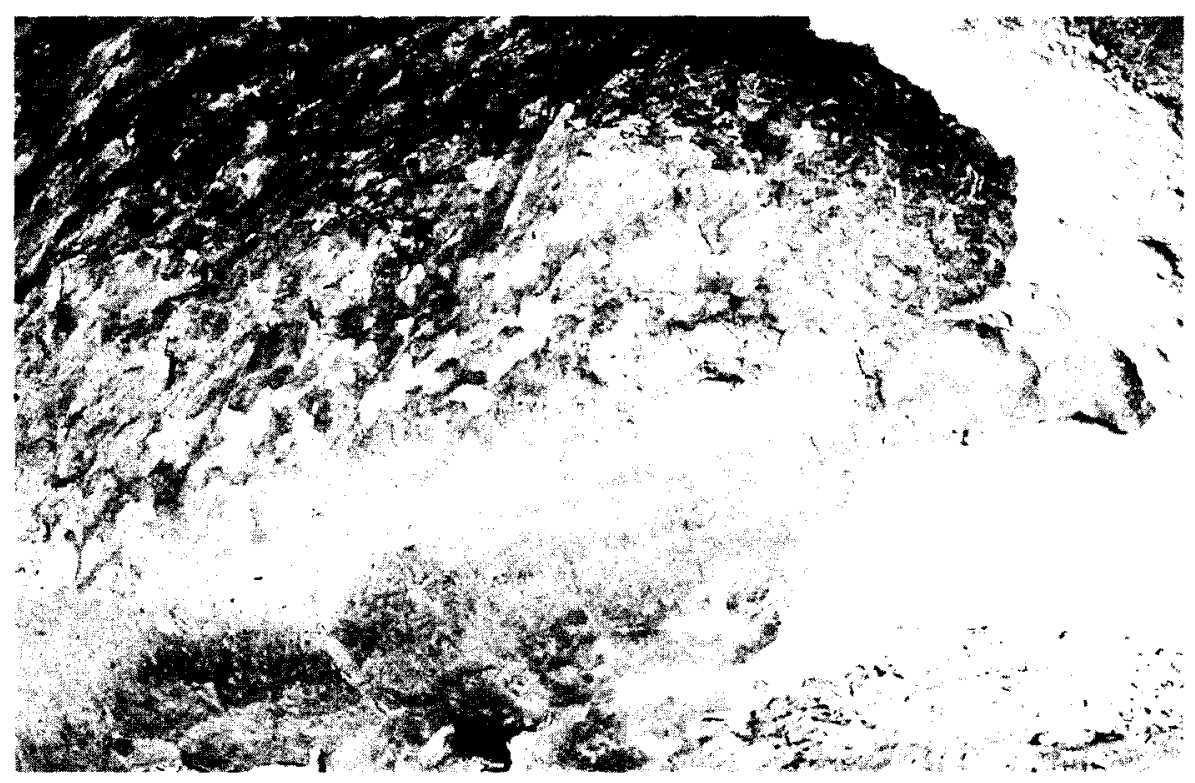

Fig. 30. Las pinturas de la Cueva de los Ladrones o Pretina 3 se encuentran sobre un soporte muy fragmentado, con abundantes desconchones. La erosión eólica ha destrozado parte de la pared del abrigo y creado, dentro de la propia cavidad, una visera muy frágil y delgada que podria romperse con los dedos. Sobre ella, en un recoveco, pudimos ver en cierta ocasión una rata campestre (RATTUS RATTUS). Al huir se desplazó rápidamente por encima de esta visera, en donde se ha creado un camino de superficie cóncava, debido a éste $u$ otros factores, en la frágil composición de la roca, prácticamente convertida ya en arena. Cabe recordar que la rata campestre construye sus madrigueras escarbando la tierra con sus propias patas si es necesario. 